\title{
Global prevalence and phylogeny of hepatitis B virus (HBV) drug and vaccine resistance mutations
}

\author{
Jolynne Mokaya ${ }^{1}$, Tetyana I Vasylyeva², Eleanor Barnes ${ }^{1,3,4}$, \\ M. Azim Ansari ${ }^{1,5}$, Oliver G Pybus ${ }^{2}$, Philippa C Matthews ${ }^{1,4,6}$
}

${ }^{1}$ Nuffield Department of Medicine, Medawar Building, South Parks Road, Oxford OX1 3SY, UK

${ }^{2}$ Department of Zoology, University of Oxford, Medawar Building, South Parks Road, Oxford OX1 3SY, UK

${ }^{3}$ Department of Hepatology, Oxford University Hospitals NHS Foundation Trust, John Radcliffe Hospital, Headley Way, Oxford OX3 9DU, UK

${ }^{4}$ National Institutes of Health Research Health Informatics Collaborative, NIHR Oxford Biomedical Research Centre, John Radcliffe Hospital, Headley Way, Oxford OX3 9DU, UK ${ }^{5}$ Wellcome Centre for Human Genetics, Roosevelt Drive, Oxford OX3 7BN, UK ${ }^{6}$ Department of Infectious Diseases and Microbiology, Oxford University Hospitals NHS Foundation Trust, John Radcliffe Hospital, Headley Way, Oxford OX3 9DU, UK

RUNNING TITLE: Global prevalence of HBV resistance mutations

\section{Correspondence: philippa.matthews@ndm.ox.ac.uk}

KEYWORDS: HBV, tenofovir, TDF, lamivudine, entecavir, NAs, NUCs, HBV vaccine, resistance, RAMs, Africa, therapy, prevention, epidemiology 


\section{ABSTRACT}

27 Introduction: Vaccination and anti-viral therapy with nucleos(t)ide analogues (NAs) are key 28 approaches to reducing the morbidity, mortality and transmission of hepatitis B virus (HBV) infection. However, the efficacy of these interventions may be reduced by the emergence of drug resistance-associated mutations (RAMs) and/or vaccine escape mutations (VEMs). We have assimilated data on the global prevalence and distribution of HBV RAMs/VEMs from publicly available data and explored the evolution of these mutations.

Methods: We analysed sequences downloaded from the Hepatitis B Virus Database, and calculated prevalence of 41 RAMs and 38 VEMs catalogued from published studies. We generated maximum likelihood phylogenetic trees and used treeBreaker to investigate the distribution of selected mutations across tree branches. We performed phylogenetic molecular clock analyses using BEAST to estimate the age of mutations.

Results: RAM M204I/V had the highest prevalence, occurring in 3.8\% (109/2838) of all HBV sequences in our dataset, and a significantly higher rate in genotype $\mathrm{C}$ sequence at $5.4 \%$ (60/1102, $p=0.0007)$. VEMs had an overall prevalence of $1.3 \%(37 / 2837)$ and had the highest prevalence in genotype $C$ and in Asia at 2.2\% (24/1102; $p=0.002)$ and $1.6 \%$ $(34 / 2109 ; p=0.009)$ respectively. Phylogenetic analysis suggested that most RAM/VEMs arose independently, however RAMs including A194T, M204V and L180M formed clusters in genotype B. We show evidence that polymorphisms associated with drug and vaccine resistance may have been present in the mid $20^{\text {th }}$ century suggesting that they can arise independently of treatment/ vaccine exposure.

Discussion: HBV RAMs/VEMs have been found globally and across genotypes, with the highest prevalence observed in genotype $C$ variants. Screening for the genotype and for resistant mutations may help to improve stratified patient treatment. As NAs and HBV vaccines are increasingly being deployed for HBV prevention and treatment, monitoring for resistance and advocating for better treatment regimens for HBV remains essential. 


\section{INTRODUCTION}

Anti-viral therapy with nucleos(t)ide analogue (NA) agents is a central approach to reducing morbidity, mortality and transmission of hepatitis B virus (HBV) infection. NAs are used to suppress viraemia, thus reducing inflammatory liver damage (1). However, the efficacy of widespread deployment of NAs, both for individual patients and at a public health level, may be affected by the emergence of drug resistance $(2,3)$. Resistance-associated mutations (RAMs) can arise as a result of the low fidelity of the HBV reverse transcriptase (RT) enzyme which lacks transcriptional proofreading activity, especially in the setting of high viral replication rates (estimated at up to $\sim 10^{12}$ virions/day (2)). Lamivudine (3TC) and entecavir (ETV) were licensed in 1986 and 2005, respectively, but their ongoing role has been limited by the occurrence of anti-viral drug resistance (4-6). Tenofovir (TFV), most commonly prescribed as tenofovir disoproxil fumarate (TDF), was licensed in 2008 and is now the favoured choice as it has a higher genetic barrier to resistance, as well as being cheap, welltolerated, and safe, including in pregnancy (4). However, there are now emerging data that show the potential for selection of TDF drug resistance mutations (7), albeit with limited insights into their prevalence or clinical impact (8). Importantly, as well as being selected in individuals on therapy, RAMs have been reported among treatment-naïve individuals $(1,9)$. Whether these mutations occur without exposure to antivirals, or are exclusively as result of prior drug exposure, is uncertain.

Reports of resistance to the HBV vaccine raise concerns about the extent to which vaccinemediated immunity will remain robust. The vaccine, licensed for use in 1981, is administered to infants as part of WHO expanded programme for immunization (10). HBV vaccination induces the production of neutralising antibodies that mainly target the second hydrophilic loop (amino acids (aa) 139 to 147 or 149) of the major antigenic determinant (aa 99 to 169) of the HBV surface protein (HBsAg) $(11,12)$. Strong immune pressure can lead to the selection of mutations within $\mathrm{HBsAg}$, resulting in variants resistant to $\mathrm{HBV}$ vaccine and/or $\mathrm{HBV}$ immunoglobulin ( $\mathrm{HBlg}$ ) (2). G145A/R is the best described mutation associated with resistance to $\mathrm{HBV}$ vaccine/HBlg (11-13). Several other mutations across the entire antigenic determinant have been reported, which also have associations with vaccine resistance $(11,14-16)$.

Genetic differences among the ten HBV genotypes (A-J) and numerous sub-genotypes may influence the likelihood of acquisition of drug or vaccine resistance (17). Genotypes have 
Africa, and $B$ and $C$ in Asia $(18,19)$. In genotypes in which the wild type amino acid at a specific position is part of a sequence motif associated with drug or vaccine resistance, the barrier to resistance is likely to be inherently lower. This phenomenon has been described in hepatitis C virus (HCV) infection, explaining why some sub-genotypes are intrinsically resistant to the most widely used direct acting antiviral drugs (20-22). In addition, genotype-specific differences in mutation rates and host population dynamics have an influence on virus evolutionary rates, which directly affects the probability of appearance of RAMs/VEMs. For $\mathrm{HBV}$, the rate of molecular evolution is estimated to be between $7.9 \times 10^{-5}$ and $3.2 \times 10^{-4}$ substitutions per site per year $(23,24)$.

A number of studies have reported the frequencies of RAMs in HBV from different populations $(1,25-27)$; however, the global prevalence, geographic distribution, time of origins, and their association with different HBV genotypes remain unknown. We therefore set out to assimilate data on the global prevalence and distribution of HBV RAMs from public sequence databases, and to explore the genetic relatedness of viruses bearing these mutations.

\section{METHODS}

\section{HBV sequences curation process}

We analysed sequences downloaded from a publicly available database (Hepatitis B Virus Database - https://hbvdb.ibcp.fr/HBVdb/ (28)), accessed on $20^{\text {th }}$ November 2018. We downloaded a total of 6,219 full length genome sequences (Suppl Figure 1). Using MEGA7 software (29), we generated neighbour joining phylogenetic trees to validate the HBV genotype assignment, discarding sequences that had been incorrectly classified. We then generated pairwise distances for aligned sequences within each genotype using the dist.alignment function of the R package seqinr (30), and excluded sequences with $>99.5 \%$ similarity in order to remove closely related isolates for instance duplicates and/or isolates derived from the same individual. For the remaining sequences, we obtained sample collection date and sampling country from GenBank. A total of 2938 sequences had geographical data and 2167 had both sample collection date and geographical data. Suppl Figure 1 shows the data curation process.

\section{Drug resistance associated mutations}

We worked from a list of pre-existing drug RAMs identified from published studies $(1,2,8,9,25,31)$ (Suppl Table 1), and stratified them according to the NA to which they cause resistance, as described below: 
a. We classified RAMs associated with 3TC into three categories: (i) primary RAMs, which are well known to cause resistance to 3TC in isolation; (ii) compensatory RAMs, which by themselves do not confer resistance but when combined with primary RAMs enhance resistance and viral functional capacity (2); and (iii) putative RAMs for which there is limited clinical/phenotypic evidence for 3TC resistance.

b. Two or more amino acid substitutions are required across the HBV RT protein to confer resistance to ETV which could occur as a combination of M204I/V with one or more of the following substitutions L80I/V, I163V, I169T, V173L, L180M, A181S/T/V, T184X, A186T,S202C/G/I/R, M250I/V and/or C256S/G.

\section{Vaccine escape mutations}

139 All pre-existing VEMs included in this study were identified from published studies $(1,14-$ 140 16,32-39) (Suppl Table 2). G145A/R and K141E/I/R have the strongest evidence base of clinical and in vitro data to support HBV vaccine resistance (33), while other VEMs are considered putative, as they are supported by less robust data.

\section{Prevalence analyses}

145 For the global prevalence analysis, we included HBV sequences with known country of 146 origin from genotypes A - E; we excluded genotypes F, G \& H from this analysis because of low sample size $(<100)$, resulting in a total of 2,838 sequences. For all polymorphisms that have been reported in association with resistance listed in Suppl Table 1 and 2, we calculated the prevalence as total number of sequences with a specified mutation out of the total number of sequences in each genotype/continent.

We carried out prevalence analysis reporting confidence intervals and $p$-values for individual RAMs common to 3TC, ETV and TFV, for individual or combined RAMs associated with ETV and TFV resistance, and for individual VEMs. We calculated confidence intervals using an online software Epitools (http://epitools.ausvet.com.au). We used Chi square test to compare the prevalence of RAMs/VEMs between different genotypes and between different continents 
161 Distribution of selected RAMs and VEMs on maximum likelihood phylogenetic trees

162 We generated maximum likelihood (ML) phylogenetic trees for HBV genotype $A(n=290), B$ $163(n=730), C(n=1102), D(n=565)$ and $E(n=150)$ sequences for which geographic information

164 was available. We used the general time reversible nucleotide substitution model with gamma165 distributed among-site rate variation (GTR + G) in IQ-TREE (40). We chose this model as it 166 incorporates different rates for every nucleotide change and different nucleotide frequencies, 167 thus allowing for most flexibility allowing us to avoid a model-selection step (41). We rooted 168 the trees using the mid.point function of the R package phangorn (42).

170 For this analysis, we considered a total of 12 RAMs (S106C/G, D134E, R153W/Q, V173L, 171 L180M, A181T/V, A194T, A200V, M204I/V, L217R, L229V/W, I269L). These RAMs were 172 selected because they are primary RAMs or have robust evidence in causing resistance to 173 3TC, ETV and/or TFV. We also considered eight VEMs (C139S, S/T140I, P142S, S/T143L/M, $174 \mathrm{D} 144 \mathrm{~A} / \mathrm{E} / \mathrm{G} / \mathrm{N}, \mathrm{G} 145 \mathrm{~A} / \mathrm{E} / \mathrm{R}, \mathrm{K} 141 \mathrm{~A} / \mathrm{/} / \mathrm{R}$ and $\mathrm{C} 147 \mathrm{~S})$ which are located within the epitope 175 (aa139 - 147) which is a neutralising epitope for the HBV vaccine.

177 We used treeBreaker (43) to test if sequences with individual mutations were randomly 178 distributed across the branches of the phylogenetic trees reconstructed for each genotype. 179 The program calculates per-branch posterior probability of having a change in the distribution 180 of a discrete character and gives a Bayes factor to show the strength of this evidence (43). A 181 Bayes factor of $>30$ indicates strong evidence that sequences with RAMs/VEMs are not 182 randomly distributed on a phylogenetic tree. We performed this analysis for each mutation 183 separately.

\section{Phylogenetic dating}

We performed phylogenetic dating to estimate the times of emergence of mutations of interest, focused on RAMs V173L, L180M and M204I/V as they are well known to cause

188 (individually or synergistically) resistance to 3TC, ETV and TDF (8), and VEMs G145A/R and $189 \mathrm{~K} 141 \mathrm{E} / \mathrm{I} / \mathrm{R}$ as they have been best described to cause HBV vaccine resistance (11-13). In 190 this analysis we included genotypes that had $>50$ sequences with associated sampling date 191 information: genotype $A(n=170), B(n=594), C(n=906), D(n=336)$ and $E(n=88)$. We manually 192 inspected sequences for misalignments in AliView program (43) and then excluded codon 193 positions associated with resistance (we excluded all sites listed in Suppl Tables 1 and 2) to ensure that parallel evolution RAMs/VEMs does not affect the phylogeny (44). We used ML

195 phylogenetic trees generated for each genotype as described above and then dated these 196 phylogenetic trees using IQ-TREE v2.0.3 (45). We resampled the trees 100 times and chose 197 lognormal relaxed molecular clock model because it has performed best in other studies of 
198

HBV evolution $(46,47)$. We used TempEst to estimate the molecular clock signal in our datasets by regressing the root-to-tip genetic distance of each sequence in the tree and its sampling date (48). Based on application of TempEst, we estimated the correlation between the dates of the tips of the sequences and the divergence from the root to be $7.8 \times 10^{-2}, 3.9$ $\times 10^{-1}, 4.3 \times 10^{-2}, 2.3 \times 10^{-2}$ and $2.1 \times 10^{-1}$ for genotypes A, B, C, D and E, respectively. Due to the lack of correlation, we used the substitution rate estimated before $(24,49)$ and therefore we thus fixed the mean substitution rate to $5.0 \times 10^{-5}$ (SD $4.12 \times 10^{-6}$ ) subs/site/year for all genotypes in all subsequent analyses. We reported the time to most recent common ancestor (TMRCA) of two or more sequences that clustered together having the same mutation as this TMRCA likely corresponds to the lower bound of the age of the mutation.

We also performed molecular clock phylogenetic analyses using Bayesian Evolutionary Analysis Sampling Trees (BEAST). This method has been described in Suppl Methods.

\section{RESULTS}

\section{i. Global prevalence of HBV drug RAMs}

We assessed the prevalence of polymorphisms associated with drug resistance across 48 different sites within RT protein in a total of 2838 full length HBV sequences, Suppl Table 1. $90 \%$ (43/48) of the sites had polymorphisms associated with drug resistance, Suppl Fig 2. $60 \%$ of the sites had polymorphisms associated with drug resistance occurring at the prevalence of between $0-10 \%$ in both genotypes and continents. Genotypes A and C, as well as Europe had the highest number of sites (nine sites for genotype $A$ and $C$, and 11 sites for Europe) with polymorphisms associated with drug resistance occurring at a prevalence of $>20 \%$, Suppl Fig 2.

\section{RAMs common to 3TC, ETV and/or TDF}

RAMs L80I/M/V, V173L, L180M, A181T/V, T184X are common to 3TC, ETV and/or TFV. M204I/V had the highest prevalence at 3.8\% (109/2838) (Figure 1A). Genotype C had the highest prevalence of all of these mutations, apart from L80I/M/V which is most common in Genotype D (although not statistically significant) (Figure 1B). L180M and M204I/V were both present in all genotypes and continents analysed in this manuscript (Figure 1B, C). However, there were no significant differences in prevalence of these RAMs across continents. 


\section{RAMs associated with ETV resistance}

235 The overall prevalence of ETV resistance in this dataset, determined by the presence of

236 RAMs M204I/V+L180M, was 2.4\% (67/2838); other combinations of ETV drug resistant

237 mutations were uncommon (all <0.6\%); Suppl Fig 3. As previously, the most common

238 resistance mutations were seen in genotype $C$ at $3.5 \%(39 / 1102$ vs $28 / 1736$ in other

239 genotypes; $p=0.001$ ).

240 RAMs associated with TFV resistance

241 The prevalence of individual mutations that have been associated with TFV resistance 242 ranged between $0.2-19.5 \%$. Compared to all other genotypes, genotype $\mathrm{C}$ had the highest 243 prevalence of individual RAMs S106C/G, DH/N134E and I269L; and Asia had the highest 244 prevalence of these individual RAMs S106C/G, DH/N134E and I269L compared to other continents, Suppl Fig 4.

Sequences with certain combinations of RAMs are likely to have the highest probability of clinically significant TFV resistance (8). We therefore sought evidence of these combinations of mutations in our sequence database $(n=2838)$. In each case, we only identified between one and three sequences with each combination of RAMs giving an overall prevalence of between $0.04 \%-0.1 \%$ (Suppl Table 3), suggesting these arise infrequently and are currently unlikely to be of significance at a population level. The majority of sequences carrying these drug resistance motifs were again in genotype C.

\section{ii. Global prevalence of VEMs}

We assessed for the prevalence of polymorphisms associated with vaccine/HBIg escape across 33 different sites within surface protein in a total of 2838 full length HBV sequences, Suppl Table 2. $78 \%(25 / 33)$ sites had polymorphisms associated with vaccine/HBIg escape, Suppl Fig 5. 52\% (12/23) of the sites had polymorphisms associated with vaccine escape occurring at the prevalence of between $0-9 \%$ in both genotypes and continents. Genotype $\mathrm{C}$ and Asia had the highest number of sites with polymorphisms associated with vaccine escape occurring at the prevalence of $>20 \%$, compared to other genotypes and continents, Suppl Fig 5.

VEM K141E/I/R was not present in our dataset. G145A/R had an overall prevalence of $1.3 \%(37 / 2837)$ and had the highest prevalence in genotype $C$ at $2.2 \%(24 / 1102 ; p=0.002)$, and in Asia at 1.6\% (34/2109; $p=0.009)$; this is the best recognised VEM (Figure 2A). Other VEMs that had an overall prevalence of $>1 \%$ were $T 118 \mathrm{~A} / \mathrm{R} / \mathrm{V}, \mathrm{M} 133 \mathrm{I} / \mathrm{L} / \mathrm{T}, \mathrm{A} 128 \mathrm{~V}$, 
269 Q129H/N/R, G145A/R, P120S/T and S/T143L/M (Figure 2A). T118A/R/V, A128V and

$270 \mathrm{~S} / \mathrm{T} 143 \mathrm{~L} / \mathrm{M}$ had the highest prevalence in genotype $\mathrm{D}$ and in Europe, being present $>3 \%$ of

271 the sequences; whereas VEMs M133I/L/T and Q129H/N/R had the highest prevalence in

272 genotype $\mathrm{B}$ and $\mathrm{M} 133 \mathrm{I} / \mathrm{L} / \mathrm{T}$ had the highest prevalence in Asia, also being present in $>3 \%$

273 of the sequences (Figure 2B and 2C).

274

\section{RAMs/VEMs as wildtype amino acid}

Determining the clinical significance of individual RAMs/VEMs in HBV sequences is difficult because some of the mutations that have been described occur at consensus level in some genotypes. For example, 11 polymorphisms associated with drug resistance and nine polymorphisms associated with vaccine escape had a prevalence of $>50 \%$ in $\geq 1$ genotype

280 (s), Suppl Table 4 and Suppl Table 5. RAM H/Y9H is wildtype in genotypes A-E. This mutation is most likely to add to resistance as flexible positions in the protein, in which compensatory change is easily incorporated. RAMs H126Y and R/W153W, which contribute to TFV resistance when combined with $\geq 3$ other RAMs (8), are wildtype in genotype $A$. This shows that resistance to different drugs or HBV vaccine might be more easily selected in certain populations or regions, based on the global distribution of HBV genotypes.

Distribution of selected RAMs and VEMs on maximum likelihood phylogenetic trees We considered the distribution of 12 RAMs (S106C/G, D134E, R153W/Q, V173L, L180M, A181T/V, A194T, A200V, M204I/V, L217R, L229V/W, I269L) and eight VEMs (C139S, S/T140I, P142S, S/T143L/M, D144A/E/G/N, G145A/E/R, K141A/I/R and C147S) across the branches of ML phylogenetic trees. Most of these RAMs and all VEMs were randomly distributed across the branches of phylogenetic trees reconstructed from genotypes A-E sequences, suggesting parallel evolution.

However, there were several RAMs that clustered within genotype $B, C$ and $D$ sequences (Figures 3). In genotype B, all sequences containing the A194T variant clustered together (Bayes factor, BF, support $>100 ; n=4$ sequences). Sequences with this RAM were all from Indonesia, reported by a study exploring HBV genetic diversity (50). Some sequences containing both M204V and L180M formed a cluster in genotype B (BF = 54.99, n=4 sequences) and some with M204l formed a cluster in genotype $D$ (BF $>100, n=3$ sequences). In genotype $C$, there were clusters of RAMs S106C (BF $>100, n=5$ sequences), $R 153 Q$ ( $B F>100, n=3$ sequences), and I129L ( $B F>100, n=34$ sequences).

303 Clustering of sequences with RAMs might suggest an emerging sublineage of treatment resistant virus. 


\section{Evolution of sequences with RAMs/VEMs}

307 Most sequences with RAMs/VEMs in our analysis were published after the approval of

$308 \mathrm{NAs} / \mathrm{HBV}$ vaccine, as a result of widespread improvements and availability of sequencing that

309 have arisen in parallel with roll out of drugs and vaccine. However, four sequences (KF214668,

310 KF214671, KF214673 and KF214676) with RAM I269L and one sequence (KF214659) with

311 VEM S/T143M were sampled from Asia in 1963, and one sequence (HQ700441) with RAM

312 L180M was sampled from Oceania in 1984, demonstrating that mutations can arise without

313 exposure to treatment or vaccination.

315 We performed ML molecular clock analysis for full datasets of sequences of genotypes A - E.

316 However, only genotype $C$ had clusters that had at least two isolates with the same resistant

317 mutations with a single common ancestor as shown in Table 1. The estimated time of

318 emergence of branches with RAMs M204V+L180M was around year 1945 (95\% HPD 1897

319 - 1971); and branches with VEM G145R was estimated to emerge around year 1930 (95\%

320 HPD 1866 - 1958). Importantly, in both cases the higher bound of the 95\% HPD interval of 321 the TMRCA of these clusters, which likely correspond to the lower bound of the estimate of 322 the age of these mutations, precedes the introduction of NAs and the HBV vaccine. The 323 results we obtained from ML molecular clock analysis and BEAST analysis were consistent.

325 DISCUSSION

326 Novel findings and comparison with previous literature

327 We describe the global prevalence of drug and vaccine resistance in HBV across genotypes

328 and geographical regions and explore the evolution of these mutations using phylogenetic 329 analysis, in order to provide a high-resolution picture of the origins and distribution of drug 330 resistance. From this analysis, HBV drug and vaccine resistance are not common, with the 331 highest frequency of individual or combined mutations that are well known to cause resistance, 332 being $\sim 4 \%$ and the majority being $<1 \%$. These mutations are distributed across various 333 continents and genotypes, with the most frequent RAMs/VEMs identified in genotype C, 334 concordant with previous studies from China $(51,52)$. We show that these mutations are not 335 only driven by exposure to drug or vaccine but are likely to have been present in some 336 sequences for hundreds of years. More studies representing all genotypes are needed, 337 alongside careful correlation with clinical evidence of drug resistance.

$339 \mathrm{M} 204 \mathrm{I} / \mathrm{V}$ is one of the best recognised drug resistance motifs in HBV and had the highest 340 overall prevalence of $3.8 \%$ within our whole sequence database. A previous meta-analysis 
341 estimated the prevalence of $\mathrm{M} 204 \mathrm{I} / \mathrm{V}$ as $4.9 \%$ among $>12,000$ treatment-naïve individuals

342 (25), and another review reported a prevalence of M204I/V of 5.9\% among 8, 435

343 treatment-naïve individuals (9). These reviews reported prevalence as the proportion of

344 individuals with mutations within the total number of treatment naïve individuals, without

345 accounting for closely related sequences (thus may include multiple sequences from a

346 single individual). In contrast, we used full length HBV sequences and excluded identical

347 sequences, which might explain the lower prevalence we report.

349 We reported the prevalence of ETV resistance as $2.4 \%$, which is slightly higher than the 350 prevalence of $1.7 \%$ reported from a large survey carried out in China among 1223 treatment 351 experienced patients and also a prevalence of $1.2 \%$ reported from a longitudinal study that 352 followed $108 \mathrm{HBV}$ infected treatment naïve individuals for five years $(26,53)$. Unlike these 353 two studies, we took a lenient approach by reporting the overall prevalence of ETV 354 resistance considering sequences with RAMs M204I/V+L180M, with or without an additional compensatory mutation. These two are always present in ETV resistant variants, and are the main ETV RAMs reported in published HBV treatment guidelines $(10,54)$.

We estimated the overall prevalence of TFV resistance to be between $0.04-0.2 \%$. There have been few studies that have reported on TFV resistance (8) and more robust data are still needed to define HBV resistance in order to guide better estimation of the prevalence of relevant RAMs.

363 The global prevalence of the VEM G145A/R in our data was $1.3 \%$, which is comparable to 364 that be $0.3-1 \%$ previously reported across genotypes A-F (55). A study carried out in Italy reported a higher prevalence of $3.1 \%$, in a cohort dominated by genotype $D$ infection (56). Regional differences might explain the difference in prevalence. However, the majority of individuals with this mutation from the Italian study were immunocompromised and it was not clear if they had been vaccinated prior to becoming infected.

\section{Relationship between genotype and drug or vaccine resistance}

371 The prevalence of RAMs/VEMs across different regions is influenced by the predominant genotype, but may also relate to different patterns of drug or vaccine exposure in the population. For example, T118A/R/V, A128V and D144A/E/G/N variants are more common in Europe, which may relate to better vaccine coverage (57) that drives the selection of resistant variants. Some polymorphisms that have been described in association with resistance are wildtype in certain genotypes, which might indicate that these genotypes are more susceptible to the development of clinically significant drug resistance. For example, 
378 TFV resistance might be selected more easily in genotype A given that RAMs H126Y and

$379 \mathrm{R} / \mathrm{W} 153 \mathrm{~W}$ are wildtype in this genotype (58).

\section{Phylogenetic analysis of selected RAMs and VEMs}

382 We provide evidence that RAMs can arise without exposure to treatment/vaccine, showing 383 that certain RAMs emerged prior to the NAs and vaccine era. Using phylogenetic dating, we 384 estimate that RAMs M204V and L180M, and VEM G145R were already present around the mid $20^{\text {th }}$ century. Although these estimates have wide confidence intervals, their upper bounds precede the time of introduction of NAs and the HBV vaccine. A previous study estimated the origin date of HBV genotype D in Iran as 1894 (95\% HPD 1701 - 1957)(47), and the root age of genotype A polymerase sequences is estimated as the year 955 (95\% HPD 381 - 1482); (46). A study that analysed 167 full length genotype E sequences, estimated the TMRCA to be 174 years (95\% HPD 36 - 441); (59). Similar to our analysis, these studies used an uncorrelated relaxed lognormal clock which is reported to the best fitting clock $(46,47,59)$. However, given the differences in the substitution models, and with some studies using sequences for just a single gene, direct comparison of the estimated TMRCA generated by these studies and our analysis is challenging.

\section{Selection vs transmission of drug resistance}

Most RAMs were randomly distributed across the branches of HBV phylogenetic trees, which suggests that these polymorphisms are being selected independently in individual hosts (parallel evolution (60)) rather than becoming fixed and disseminated from a founder strain.

400 The high viral replication and mutation rate of HBV can result in amino acid substitutions at sites of resistance, leading to the stochastic emergence of drug RAMs even in individuals who have not been exposed to treatment (61-63). Individuals can also be infected with HBV strains containing drug RAMs which could significantly comprise virological response to therapy, as has been shown in HIV (64).

405

\section{Caveats and limitations}

407 The major constraint in this work is the relative lack of HBV sequence data; given the huge

408 global burden of infection there is a striking lack of high-quality sequence data available in the 409 public domain. As our sequences were obtained from GenBank, metadata on individual 410 characteristics and treatment exposure were not available. Our analyses may not be 411 representative, given the biased nature of sequence data that are available, disproportionately 412 representing certain populations and regions, and samples containing high viral load (65). 413 Drug resistant sequences may be over-represented, given that virus suppressed by drug 
414 therapy is not accessible for sequencing and individuals with break-through viraemia on

415 treatment are more likely to have samples submitted for sequence analysis.

416

417 Phylogenetic dating in HBV is challenging. Its overlapping reading frame raises controversies

418 around its evolution rates. HBV sequences lack temporal signal thus making it challenging to

419 reliably date HBV evolution using molecular clock methods. In addition, estimation of TMRCA

420 uses sample collection dates obtained from GenBank, which may not be accurate.

While Asia and Africa are known to have the highest prevalence of chronic HBV infection worldwide at 6.2 and $6.1 \%$ respectively (66), 74\% (2109/2838) of sequences included in this analysis were from Asia and only 10\% (277/2838) published from Africa. This low representation of sequences highlights HBV as a neglected disease, with very few individuals diagnosed and linked to care (67). In addition, the influence of the widespread use of antiretroviral drugs containing 3TC and TFV, on suppression and/or emergence of drug resistance is not yet understood.

\section{Conclusions}

432 Despite the availability of effective prevention and treatment strategies for HBV infection, 433 emergence of RAMs and VEMs may pose a challenge to the achievement of the United 434 Nations sustainable development goals for elimination by 2030 . Going forward, enlarged 435 sequencing datasets, collected together with treatment histories and clinical data, will be 436 essential to develop an understanding of the distribution, nature and significance of drug resistance at an individual and population level.

\section{COMPETING INTERESTS}

$440 \quad$ No competing interests were disclosed.

\section{GRANT INFORMATION}

443 This work was supported by the Leverhulme Trust to JM, the Wellcome Trust [110110] to 444 PCM, the Medical Research Council UK to EB, the Oxford NIHR Biomedical Research Centre 445 to EB. EB is an NIHR Senior Investigator. The views expressed in this article are those of the 446 author and not necessarily those of the NHS, the NIHR, or the Department of Health. MAA is 447 Wellcome Trust Sir Henry Dale Fellow (220171/Z/20/Z). 
448 The funders had no role in study design, data collection and analysis, decision to publish, or

449 preparation of the manuscript.

450

\section{AUTHOR CONTRIBUTIONS}

452 Conceived the study: JM, PCM. Assimilated data: JM, MAA. Analysed the data: JM, TIV, MAA.

453 Wrote the manuscript: JM, TIV, PCM. Revised the manuscript: JM, TIV, EB, MAA, OP, PCM.

454 All authors have read and approved the manuscript. 


\section{REFERENCES}

1. Mokaya J, McNaughton AL, Hadley MJ, Beloukas A, Geretti A-M, Goedhals D, et al. A systematic review of hepatitis $B$ virus (HBV) drug and vaccine escape mutations in Africa: A call for urgent action. Schibler M, editor. PLoS Negl Trop Dis. 2018 Aug 6;12(8):e0006629.

2. Beloukas A, Geretti AM. Hepatitis B Virus Drug Resistance. In: Antimicrobial Drug Resistance. Cham: Springer International Publishing; 2017. p. 1227-42.

3. Fung J, Lai C-L, Seto W-K, Yuen M-F. Nucleoside/nucleotide analogues in the treatment of chronic hepatitis B. J Antimicrob Chemother. 2011;66(12):2715-25.

4. Clements CJ, Coghlan B, Creati M, Locarnini S, Tedder RS, Torresi J. Global control of hepatitis B virus: Does treatment-induced antigenic change affect immunization? Vol. 88, Bulletin of the World Health Organization. 2010. p. 66-73.

5. Pol S, Lampertico P. First-line treatment of chronic hepatitis $B$ with entecavir or tenofovir in "real-life" settings: From clinical trials to clinical practice. Vol. 19, Journal of Viral Hepatitis. 2012. p. 377-86.

6. World Health Organisation. Application for WHO Model List of Essential Medicines: Entecavir. https://www.who.int/selection_medicines/committees/expert/20/applications/Entecavi r.pdf?ua $=1$

7. Park E-S, Lee AR, Kim DH, Lee J-H, Yoo J-J, Ahn SH, Sim H, Park S, Kang HS, Won $J$, et al. (2019). Identification of a quadruple mutation that confers tenofovir resistance in chronic hepatitis B patients. J Hepatol.70:1093-1102.

8. Mokaya J, McNaughton AL, Bester PA, Goedhals D, Barnes E, Marsden BD, et al. Hepatitis B virus resistance to tenofovir: fact or fiction? A synthesis of the evidence to date. medRxiv. 2019 Oct 18;19009563.

9. Choi Y-M, Lee S-Y, Kim B-J. Naturally occurring hepatitis B virus reverse transcriptase mutations related to potential antiviral drug resistance and liver disease progression. World J Gastroenterol. 2018;24(16):1708-24.

10. World Health Organisation. WHO issues its first hepatitis B treatment guidelines. 2015. http://www.who.int/mediacentre/news/releases/2015/hepatitis-b-guideline/en/

11. Romanò L, Paladini S, Galli C, Raimondo G, Pollicino T, Zanetti AR. Hepatitis B vaccination. Hum Vaccin Immunother. 2015;11(1):53-7.

12. Ahmed Said ZN, Abdelwahab KS. Induced immunity against hepatitis B virus. World Journal of Hepatology. 2015;7:1660-70.

13. Zanetti AR, Tanzi E, Manzillo G, Maio G, Sbreglia C, Caporaso N, et al. Hepatitis B variant in Europe. Lancet. 1988;2:1132-3. 
14. Lazarevic I. Clinical implications of hepatitis B virus mutations: recent advances. World J Gastroenterol. 2014;20(24):7653-64.

15. Colagrossi L, Hermans LE, Salpini R, Di Carlo D, Pas SD, Alvarez M, et al. Immuneescape mutations and stop-codons in HBsAg develop in a large proportion of patients with chronic HBV infection exposed to anti-HBV drugs in Europe. BMC Infect Dis. 2018;18(1):251.

16. Coppola N, Onorato L, Minichini C, Di Caprio G, Starace M, Sagnelli C, et al. Clinical significance of hepatitis B surface antigen mutants. World Journal of Hepatology. 2015;7:2729-39.

17. Kramvis A. Genotypes and Genetic Variability of Hepatitis B Virus. Intervirology.2014;57(3-4):141-50.

18. Sunbul M. Hepatitis B virus genotypes: global distribution and clinical importance. World J Gastroenterol. 2014;20(18):5427-34.

19. Rajoriya N, Combet C, Zoulim F, Janssen HLAA. How viral genetic variants and genotypes influence disease and treatment outcome of chronic hepatitis $\mathrm{B}$. Time for an individualised approach?. Elsevier B.V.2017:1281-97.

20. Davis C, Mgomella GS, da Silva Filipe A, Frost EH, Giroux G, Hughes J, et al. Highly Diverse Hepatitis C Strains Detected in Sub-Saharan Africa Have Unknown Susceptibility to Direct-Acting Antiviral Treatments. Hepatology. 2019;69(4):1426-41.

21. Fourati S, Rodriguez C, Hézode C, Soulier A, Ruiz I, Poiteau L, et al. Frequent Antiviral Treatment Failures in Patients Infected With Hepatitis C Virus Genotype 4, Subtype 4r. Hepatology. 2019;69(2):513-23.

22. Rose R, Markov P V., Lam TT, Pybus OG. Viral evolution explains the associations among hepatitis $C$ virus genotype, clinical outcomes, and human genetic variation. Infect Genet Evol. 2013 Dec 1;20:418-21.

23. Bouckaert R, Alvarado-Mora MVM V., Pinho JRR, Rebello Pinho JR. Evolutionary rates and HBV: Issues of rate estimation with Bayesian molecular methods. Antivir Ther. 2013;18:497-503.

24. Osiowy C, Giles E, Tanaka Y, Mizokami M, Minuk GY. Molecular Evolution of Hepatitis B Virus over 25 Years. J Virol. 2006 Nov 1;80(21):10307-14.

25. Zhang Q, Liao Y, Cai B, Li Y, Li L, Zhang J, et al. Incidence of natural resistance mutations in naive chronic hepatitis $B$ patients: A systematic review and meta-analysis. J Gastroenterol Hepatol. 2015;30(2):252-61.

26. Meng T, Shi X, Gong X, Deng H, Huang Y, Shan X, et al. Analysis of the prevalence of drug-resistant hepatitis $B$ virus in patients with antiviral therapy failure in a Chinese tertiary referral liver centre (2010-2014). J Glob Antimicrob Resist. 2017;8:74-81. 
analysis of the prevalence of drug-resistant Hepatitis B virus in antiviral therapyexperienced patients in Europe (CAPRE). J Infect Dis. 2016;213(1):39-48.

28. Hayer J, Jadeau F, Deléage G, Kay A, Zoulim F, Combet C. HBVdb: A knowledge database for Hepatitis B Virus. Nucleic Acids Res. 2013 Jan 1;41(D1).

29. Kumar S, Stecher G, Tamura K. MEGA7: Molecular Evolutionary Genetics Analysis Version 7.0 for Bigger Datasets. Mol Biol Evol. 2016;33(7):1870-4.

31. Caligiuri P, Cerruti R, Icardi G, Bruzzone B. Overview of hepatitis B virus mutations and their implications in the management of infection. Vol. 22, World Journal of Gastroenterology. Baishideng Publishing Group Co., Limited; 2016. p. 145-54.

32. Waters JA, Kennedy M, Voet P, Hauser P, Petre J, Carman W, et al. Loss of the common " $A$ " determinant of hepatitis $B$ surface antigen by a vaccine-induced escape mutant. J Clin Invest. 1992;90(6):2543-7.

33. Carman WF. The clinical significance of surface antigen variants of hepatitis $B$ virus. Journal of viral hepatitis. 1997;4(1):11-20.

34. Steward MW, Partidos CD, D'Mello F, Howard CR. Specificity of antibodies reactive with hepatitis B surface antigen following immunization with synthetic peptides. Vaccine.1993;11(14):1405-14.

35. Protzer-Knolle U, Naumann U, Bartenschlager R, Berg T, Hopf U, Zum Buschenfelde $\mathrm{KHM}$, et al. Hepatitis B virus with antigenically altered hepatitis B surface antigen is selected by high-dose hepatitis B immune globulin after liver transplantation. Hepatology. 1998;27(1):254-63.

36. Ngui SL, O'Connell S, Eglin RP, Heptonstall J, Teo CG. Low Detection Rate and Maternal Provenance of Hepatitis B Virus S Gene Mutants in Cases of Failed Postnatal Immunoprophylaxis in England and Wales. J Infect Dis. 1997;176(5):1360-5.

37. Roznovsky L, Harrison TJ, Fang ZL, Ling R, Lochman I, Orsagova I, et al. Unusual hepatitis B surface antigen variation in a child immunised against hepatitis B. J Med Virol. 2000;61(1):11-4.

38. Chang MH. Breakthrough HBV infection in vaccinated children in Taiwan: Surveillance for HBV mutants. Antiviral Therapy. 2010;15:463-9.

39. Howard CR. The structure of hepatitis B envelope and molecular variants of hepatitis B virus. Journal of Viral Hepatitis. 1995;2:165-70.

40. Nguyen L-T, Schmidt HA, von Haeseler A, Minh BQ. IQ-TREE: A Fast and Effective Stochastic Algorithm for Estimating Maximum-Likelihood Phylogenies. Mol Biol Evol. 2015;32(1):268-74.

41. Abadi S, Azouri D, Pupko T, Mayrose I. Model selection may not be a mandatory step for phylogeny reconstruction. Nat Commun. 2019;10(1):1-11. 
42. Package "phangorn" Title Phylogenetic Reconstruction and Analysis. 2019. https://github.com/KlausVigo/phangorn

43. Azim Ansari M, Didelot X. Bayesian inference of the evolution of a phenotype distribution on a phylogenetic tree. Genetics. 201;204(1):89-98.

44. Matthews PC, Leslie AJ, Katzourakis A, Crawford H, Payne R, Prendergast A, et al. HLA Footprints on Human Immunodeficiency Virus Type 1 Are Associated with Interclade Polymorphisms and Intraclade Phylogenetic Clustering. J Virol. 2009;83(9):4605-15.

45. To TH, Jung M, Lycett S, Gascuel O. Fast Dating Using Least-Squares Criteria and Algorithms. Syst Biol. 2016;65(1):82-97.

46. Zehender G, Svicher V, Gabanelli E, Ebranati E, Veo C, Lo Presti A, et al. Reliable timescale inference of HBV genotype A origin and phylodynamics. Infect Genet Evol. 2015;32:361-9.

47. Mozhgani S-HH, Malekpour SA, Norouzi M, Ramezani F, Rezaee SA, Poortahmasebi $\mathrm{V}$, et al. Molecular evolution and phylodynamics of hepatitis $B$ virus infection circulating in Iran. Arch Virol. 2018;163(6):1479-88.

48. Rambaut A, Drummond AJ, Xie D, Baele G and Suchard MA. Posterior summarisation in Bayesian phylogenetics using Tracer 1.7. Systematic Biology. 2018; syy032.

49. Littlejohn M, Locarnini S, Yuen L. Origins and Evolution of Hepatitis B Virus and Hepatitis D Virus. Cold Spring Harb Perspect Med. 2016 Jan 1;6(1):a021360.

50. Thedja MD, Muljono DH, Nurainy N, Sukowati CHC, Verhoef J, Marzuki S. Ethnogeographical structure of hepatitis B virus genotype distribution in Indonesia and discovery of a new subgenotype, B9. Arch Virol. 2011;156(5):855-68. 55.

51. Zhang X, Chen X, Wei M, Zhang C, Xu T, Liu L, et al. Potential resistant mutations within HBV reverse transcriptase sequences in nucleos(t)ide analogues-experienced patients with hepatitis B virus infection. Sci Rep. 2019 Dec 1;9(1).

52. Li X, Liu Y, Xin S, Ji D, You S, Hu J, et al. Comparison of Detection Rate and Mutational Pattern of Drug-Resistant Mutations Between a Large Cohort of Genotype B and Genotype C Hepatitis B Virus-Infected Patients in North China. Microb Drug Resist. 2017;23(4):516-22.

53. Tenney DJ, Rose RE, Baldick CJ, Pokornowski KA, Eggers BJ, Fang J, et al. Longterm monitoring shows hepatitis $B$ virus resistance to entecavir in nucleoside-naïve patients is rare through 5 years-of therapy. Hepatology. 2009;49(5):1503-14.

54. EASL. Clinical Practice Guidelines on the management of hepatitis B virus infection. infection/English-report.pdf

55. Q. M, Ma Q, Wang Y. Comprehensive analysis of the prevalence of hepatitis B virus 
602

603

604

605

606

607

608

609

610

611

612

613

614

615

616

617

618

619

620

621

622

623

624

625

626

627

628

629

630

631

632

633

634

635

escape mutations in the major hydrophilic region of surface antigen. J Med Virol. 2012;84(2):198-206.

56. Sticchi L, Caligiuri P, Cacciani R, Alicino C, Bruzzone B. Epidemiology of HBV S-gene mutants in the Liguria Region, Italy. Hum Vaccin Immunother. 2013;9(3):568-71.

57. World Health Organisation. Global hepatitis report, 2017. https://www.who.int/hepatitis/publications/global-hepatitis-report2017/en/

58. Lee HW, Chang HY, Yang SY, Kim HJ. Viral evolutionary changes during tenofovir treatment in a chronic hepatitis $B$ patient with sequential nucleos(t)ide therapy. J Clin Virol. 2014;60(3):313-6.

59. Andernach IE, Hunewald OE, Muller CP. Bayesian inference of the evolution of HBV/E. PLoS One. 2013;8(11):e81690.

60. Gutierrez B, Escalera-Zamudio M, Pybus OG. Parallel molecular evolution and adaptation in viruses.Current Opinion in Virology. 2019;34:90-6.

61. Khudyakov Y. Coevolution and HBV drug resistance. Antivir Ther. 2010;15:505-1

62. Thai H, Campo DS, Lara J, Dimitrova Z, Ramachandran S, Xia G, et al. Convergence and coevolution of hepatitis $B$ virus drug resistance. Nat Commun. 2012;3:789.

63. Zoulim F, Locarnini S. Hepatitis B Virus Resistance to Nucleos(t)ide Analogues. Gastroenterology. 2009;137(5):1593-1608.e2.

64. Hong SY, Nachega JB, Kelley K, Bertagnolio S, Marconi VC, Jordan MR. The Global Status of HIV Drug Resistance: Clinical and Public-Health Approaches for Detection, Treatment and Prevention. Infect Disord Drug Targets. 2011;11(2):124. 68.

65. McNaughton AL, Roberts HE, Bonsall D, de Cesare M, Mokaya J, Lumley SF, et al. Illumina and Nanopore methods for whole genome sequencing of hepatitis $B$ virus (HBV). Sci Rep. 2019;9(1):7081.

66. World Health Organisation. Combating hepatitis B and C to reach elimination by 2030 may 2016 advocacy

brief http://apps.who.int/iris/bitstream/10665/206453/1/WHO_HIV_2016.04_eng.pdf

67. O'Hara GAGA, McNaughton ALAL, Maponga T, Jooste P, Ocama P, Chilengi R, et al. Hepatitis B virus infection as a neglected tropical disease. Beasley DWC, editor. 2017;11(10):e0005842.

68. McNaughton AL, Revill PA, Littlejohn M, Matthews PC, Azim Ansari M. Analysis of genomic-length HBV sequences to determine genotype and subgenotype reference sequences. J Gen Virol. 2020;101(3):271-83. 


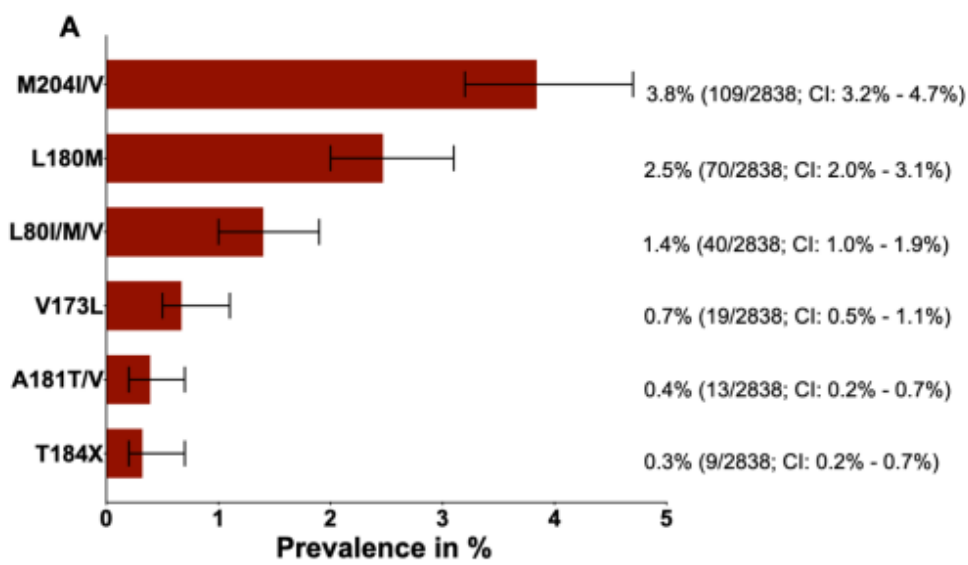

B

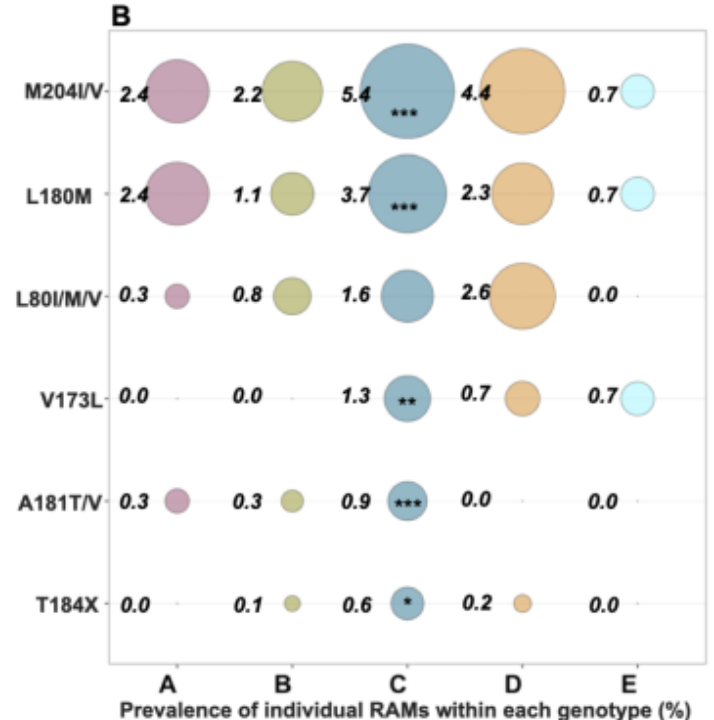

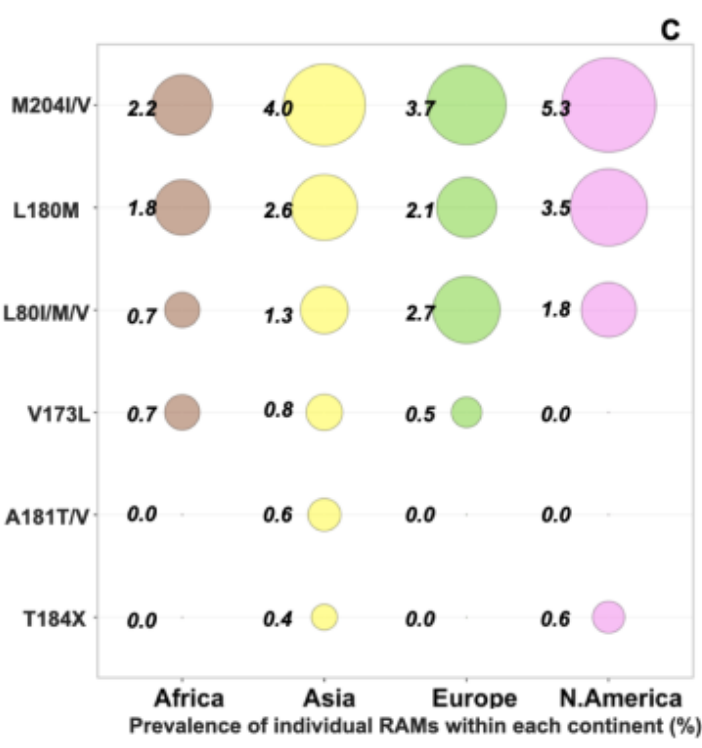

Figure 1: Global prevalence of hepatitis $B$ virus (HBV) drug resistance associated mutations (RAMs) obtained from analysing 2838 HBV sequences with information on country of origin, downloaded from a public database (https://hbvdb.ibcp.fr/HBVdb/). A. Overall prevalence of RAMs common to 3TC, ETV and TFV. B. A bubble plot showing the overall prevalence of RAMs common to 3TC, ETV and TFV within each genotype (genotype A $n=290$; Genotype B n=730; Genotype C n=1102; Genotype D n=566; Genotype E n=150). C. A bubble plot showing the overall prevalence of RAMs common to 3TC, ETV and TFV within each continent (Africa $n=277$; Asia $n=2109$; Europe $n=187$; North America $n=170$ ).

Numbers next to the circles are prevalence (\%) of individual RAMs in each genotype/continent. The asterisks $\left({ }^{* *} / * * / *\right)$ within certain circles indicate RAMs that have a higher prevalence within the specified genotype/continent compared to the prevalence of that RAM in other genotypes/continents and is statistically significant.

${ }^{* * *} p$ value $<0.001 ;{ }^{* *} p$ value $<0.005 ;{ }^{*} p$ value $<0.05$. Bars show $95 \%$ confidence intervals. T184X represents $\mathrm{T} 184 \mathrm{~A} / \mathrm{C} / \mathrm{F} / \mathrm{G} / \mathrm{I} / \mathrm{L} / \mathrm{M} / \mathrm{S}$. 


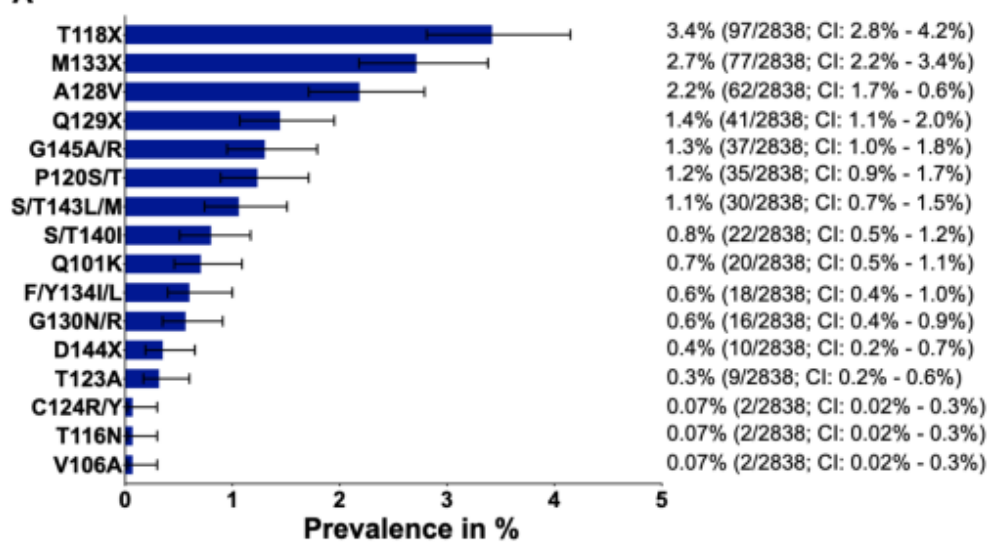

\section{B}

\begin{tabular}{|c|c|c|c|c|c|}
\hline & D & & & & \\
\hline T118X & 0.0 & 0.0 & 0.2 & $16.6_{* * *}$ & 0.7 \\
\hline M133X & $1.4{ }^{\circ}$ & $6.0_{t .0}$ & $2.0 \bigcirc$ & $0.5 \circ$ & 2.7 \\
\hline A128V & 0.0 & 0.1 & 0.1 & $10.2 \ldots * *$ & 1.3 \\
\hline Q129X & $0.7 \circ$ & $2.9 \ldots$ & $0.7 \circ$ & $1.6 \odot$ & 0.7 \\
\hline G145A/R & 0.3 & $1.0 \circ$ & $2.2 \theta$ & $0.9 \circ$ & 0.0 \\
\hline $\mathrm{P} 120 \mathrm{~S} / \mathrm{T}$ & 2.40 & 0.8 & 0.5 & $2.6 \%$ & 0.7 。 \\
\hline $\mathrm{S} / \mathrm{T} 143 \mathrm{~L} / \mathrm{M}$ & $1.0 \circ$ & $1.4 \bigcirc$ & 0.2 & $2.7 \approx$ & 0.0 \\
\hline $\mathrm{S} / \mathrm{T} 140 \mathrm{I}$ & 0.3 & $1.4 \bigcirc$ & 0.5 & $1.1 \odot$ & 0.0 \\
\hline Q101K & 0.0 & 0.0 & 1.80 & 0.0 & 0.0 \\
\hline$F / Y 134 I / L$ & 1.40 & 0.5 & $0.6 \circ$ & 0.0 & 0.7 \\
\hline G130N/R & $1.0 \circ$ & $0.7 \bullet$ & $0.5 \circ$ & $0.4^{\circ}$ & 0.7 \\
\hline D144X & $0.7 \circ$ & 0.1 & 0.2 & 0.4 。 & $2.0 *$ \\
\hline T123A & 0.0 & 0.7 & 0.3 . & 0.0 & 0.7 \\
\hline & A & $\begin{array}{c}\text { B } \\
\text { Prevalen } \\
\text { within }\end{array}$ & $\begin{array}{c}\text { C } \\
\text { f indivi } \\
\text { h geno }\end{array}$ & $\begin{array}{l}\text { D } \\
\text { VEMs } \\
(\%)\end{array}$ & $\mathrm{E}$ \\
\hline
\end{tabular}

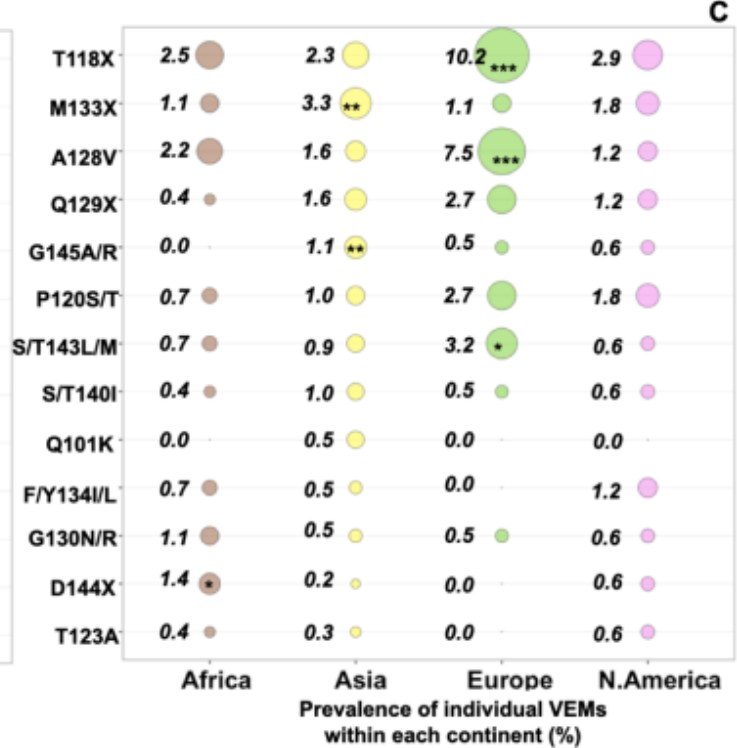
downloaded from a public database (https://hbvdb.ibcp.fr/HBVdb/). A. Overall prevalence of putative VEMs and/or VEMs with only clinical or in vitro evidence. B. A bubble plot showing the overall prevalence of putative VEMs and/or VEMs with only clinical or in vitro evidence within each genotype (genotype A n=290; Genotype B n=730; Genotype C; $=1102$; Genotype D n=566 and Genotype E $\mathrm{n}=150$ ), with a prevalence of $>0.1 \%$.

C. A bubble plot showing the overall prevalence of putative VEMs and/or VEMs with only clinical or in vitro evidence within each continent (Africa $n=277$; Asia $n=2109$; Europe; $n=187$ and North America $n=170$ ), with a prevalence of $>0.1 \%$. Numbers next to the circles are prevalence $(\%)$ of individual RAMs in each genotype/continent. The asterisks $\left({ }^{* * * / * * / *}\right)$ within certain circles indicate RAMs that have a higher prevalence within the specified genotype/continent compared to the prevalence of that RAM in other genotypes/continents and is statistically significant. ${ }^{* * *} p$ value $<0.001 ;{ }^{* *} p$ value $<0.005 ;{ }^{*} p$ value $<0.05$. T118X represents $T 118 A / R / V ; M 133 X$ represents M133I/L/T; Q129X represents Q129A/R; D144X represents D144A/E/G/N. 


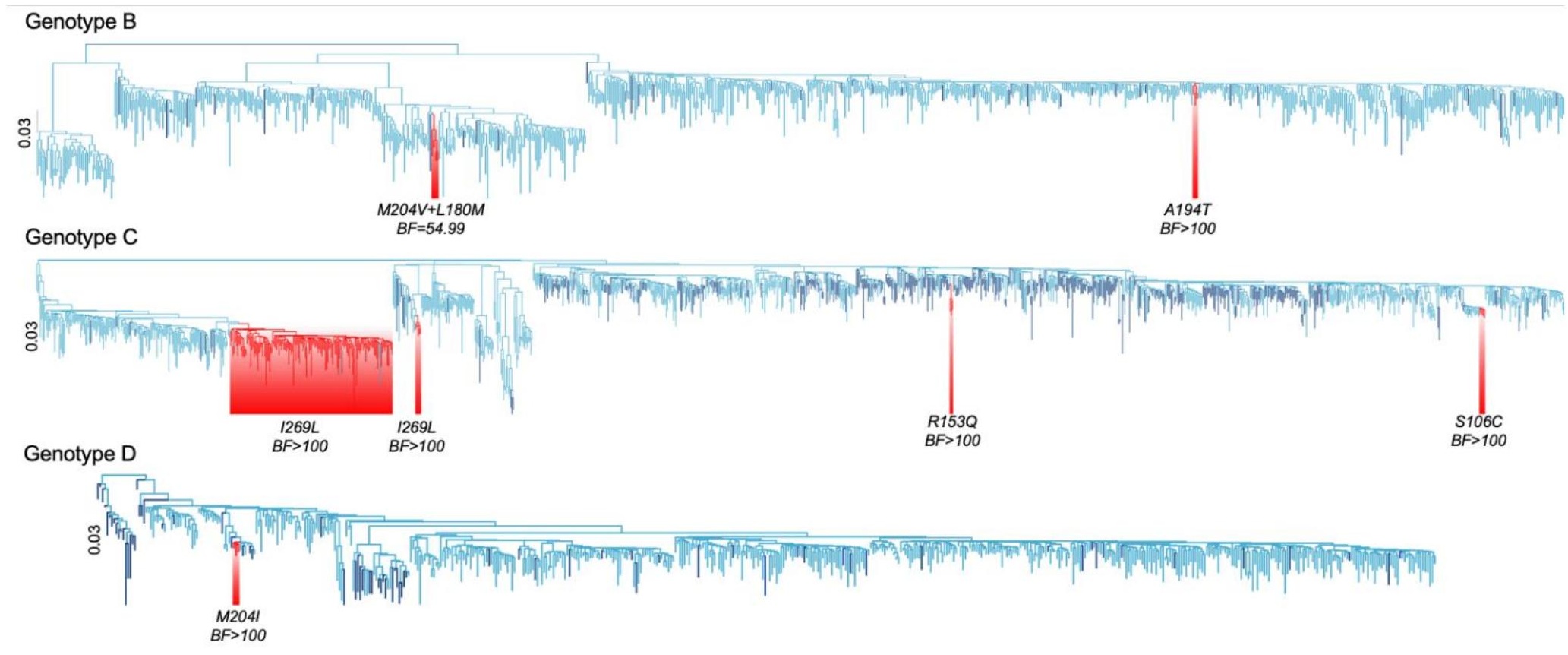

667

668

Figure 3: HBV RAMs/VEMs distribution on rooted maximum likelihood phylogenetic trees

669 for genotype B, C and D. Branches in dark blue represent sequences with one or more

670 RAMs/VEMs. Branches in light blue have no specified RAMs/VEMs. Branches highlighted in red

671 indicate clustered sequences with a RAM with Bayes factor of $>30$, suggesting strong evidence of

672 clustering. $M L$ trees for genotype $A$ and $E$ were not displayed because they had no sequences with

673 specified RAM/VEM which formed clusters. 


\section{Tables}

675 Table 1: Estimated time of the most common recent ancestor (TMRCAs) (and 95\% HPD)

676 of branches with specific RAMs/VEMs on molecular clock trees. HPD: Highest Posterior

677 Density. Only genotype $C$ is displayed because it had at least two isolates with the same

678 resistant mutations with a single common ancestor.

\begin{tabular}{|l|l|l|l|}
\hline Genotype & RAMs/VEMs & $\begin{array}{l}\text { Cluster of isolates with } \\
\text { specified RAMs/VEMs }\end{array}$ & $\begin{array}{l}\text { Estimated TMRCAs } \\
\text { (95\%HPD) }\end{array}$ \\
\hline C & M204V+L180M & FJ032355 & $1945(1897,1971)$ \\
\cline { 3 - 3 } & & FJ386620 & $1930(1866,1958)$ \\
\cline { 2 - 3 } & G145R & KU964229 & \\
\cline { 3 - 4 } & & KU964230 & \\
\hline
\end{tabular}




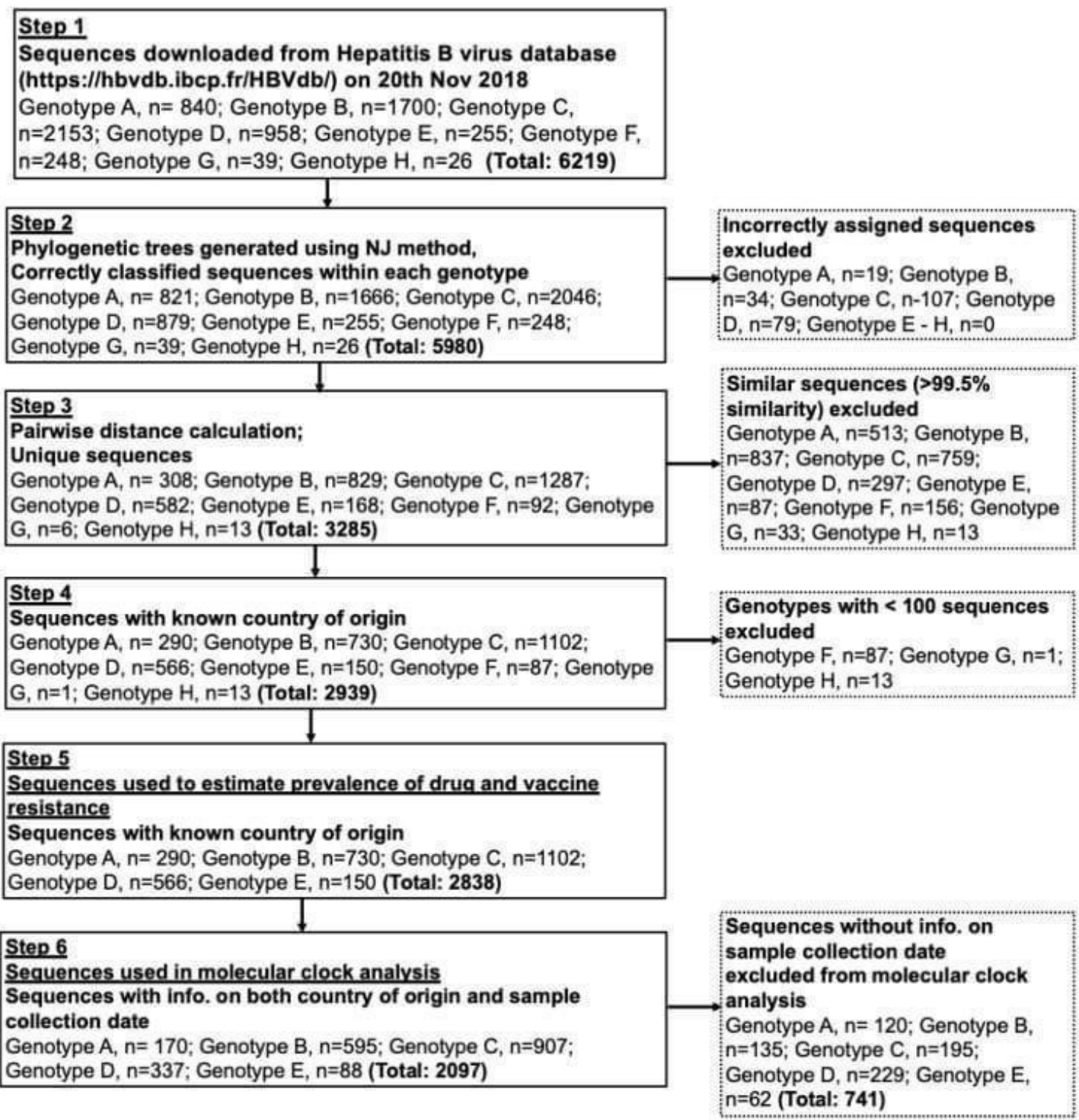
public database (https://hbvdb.ibcp.fr/HBVdb/) included in the analysis of the global 

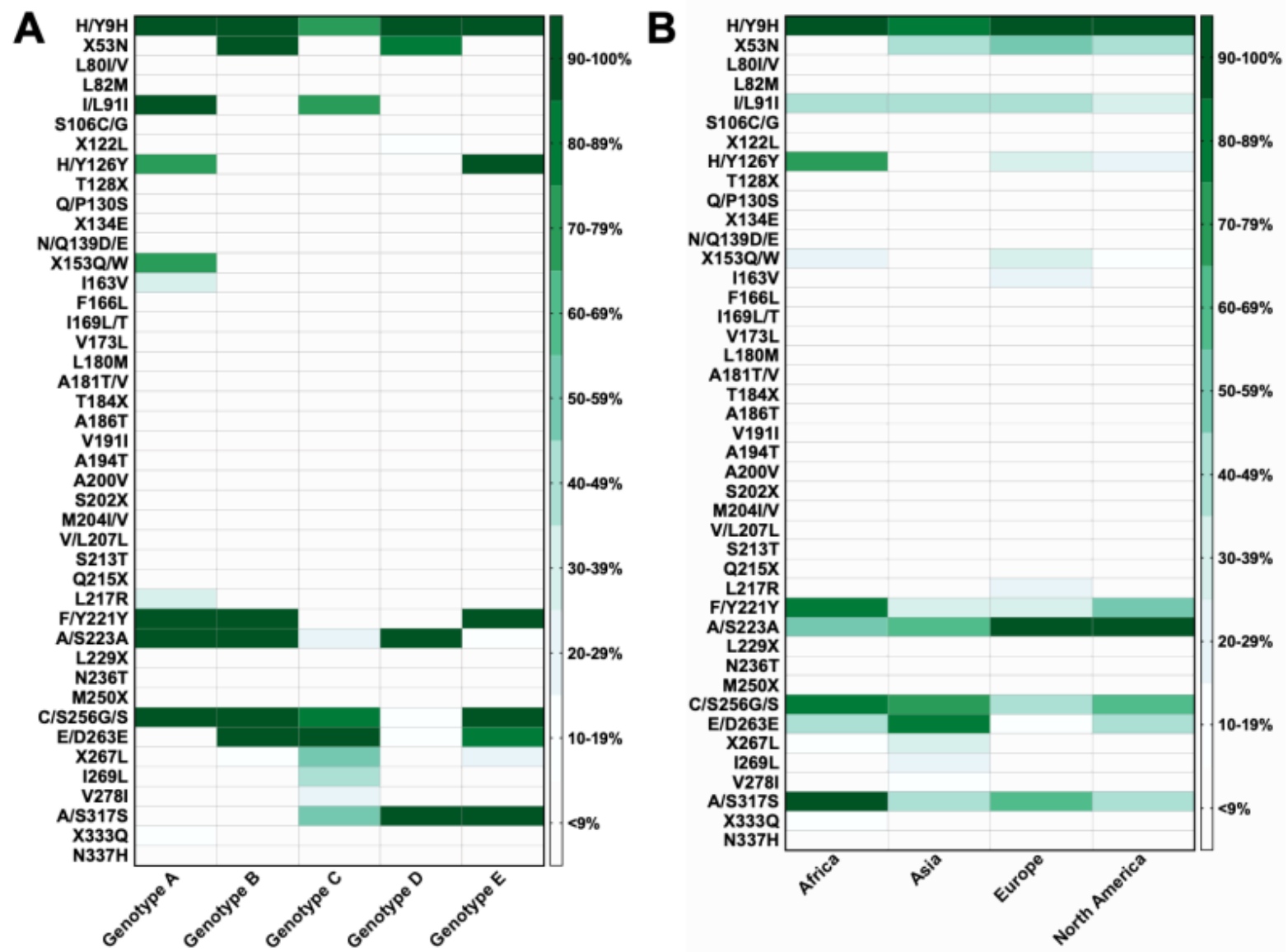
downloaded from a public database (https://hbvdb.ibcp.fr/HBVdb/). A. Prevalence of polymorphisms across genotypes; B. Prevalence of polymorphisms across continents. X134E represents D/H/N134E; X153Q/W represents Q/R/W153Q/W; T184X represents T184A/C/F/G/I/L/M/S; S202X represents S202C/G/l; Q215X represents Q215E/H/P/S; L229X represents L229G/F/V/W; M250X represents M250I/L/V; X267L represents H/L/M/Q267L. 
B

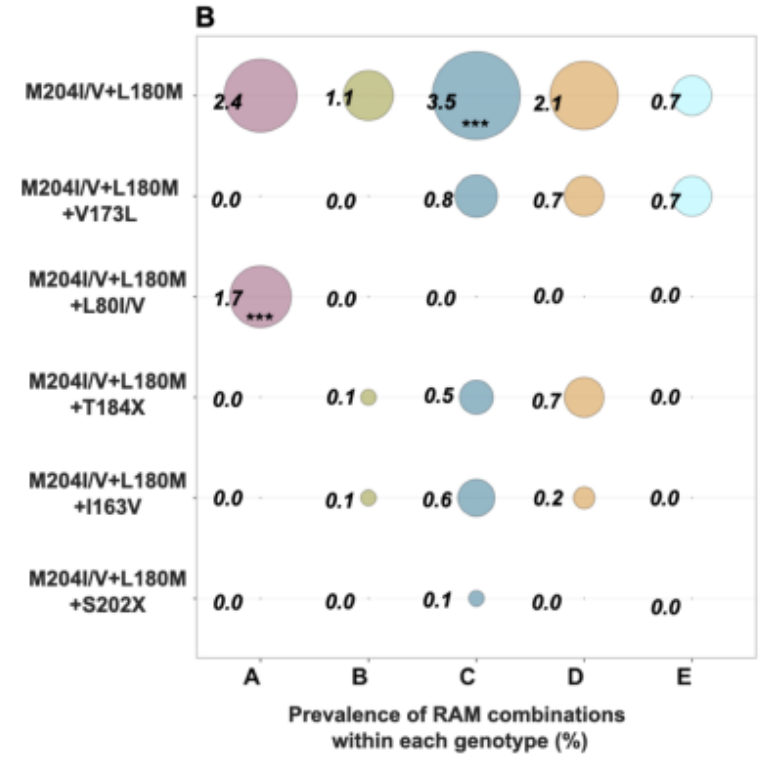

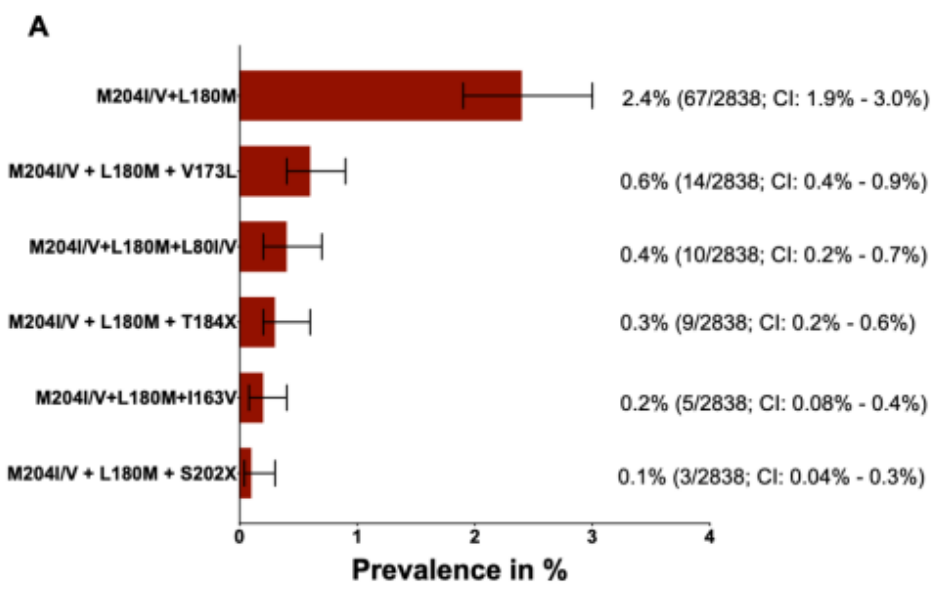

C

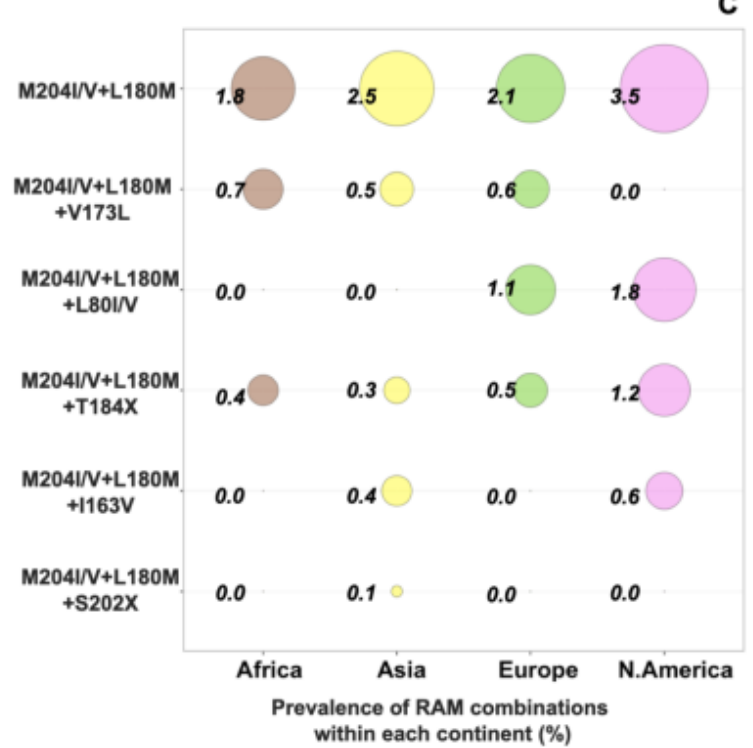

Suppl Fig 3: Global prevalence of hepatitis B virus (HBV) entecavir (ETV) resistance associated mutations (RAMs) obtained from analysing $2838 \mathrm{HBV}$ sequences with information on country of origin, downloaded from a public database (https://hbvdb.ibcp.fr/HBVdb/). A. Overall prevalence of ETV RAMs. B. A bubble plot showing the prevalence of ETV RAMs within each genotype (genotype A n=290; Genotype B n=730; Genotype C; $n=1102$; Genotype $D n=566$ and Genotype $E \mathrm{n}=150$ ). C. A bubble plot showing the prevalence of ETV RAMs within each continent (Africa $n=277$; Asia $n=2109$; Europe; $n=187$ and North America $n=170$ ). Numbers next to the circles are prevalence $(\%)$ of individual RAMs in each genotype/continent. The asterisks $\left({ }^{* *} /{ }^{* *} / *\right)$ within certain circles indicate RAMs that have a higher prevalence within the specified genotype/continent compared to the prevalence of that RAM in other genotypes/continents and is statistically significant. 


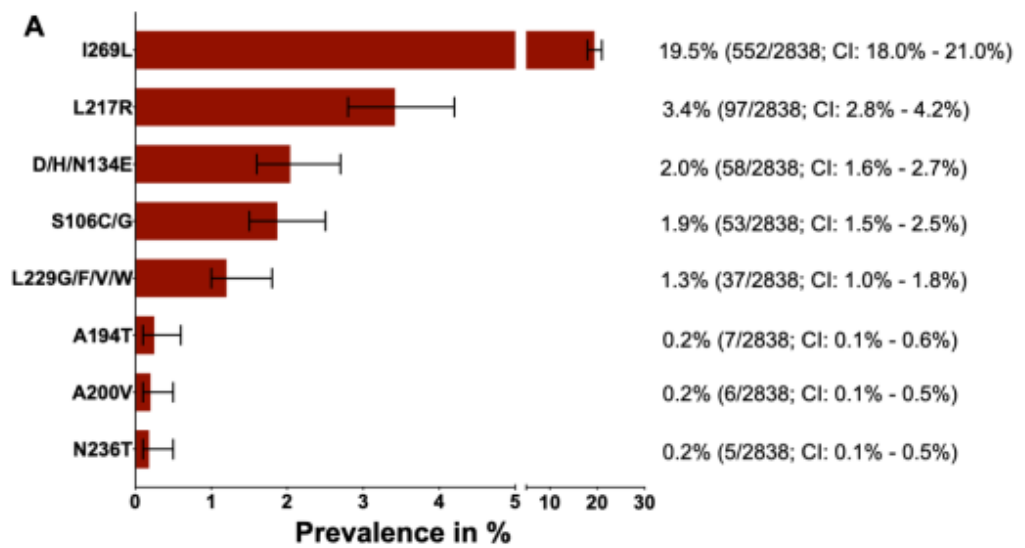

B

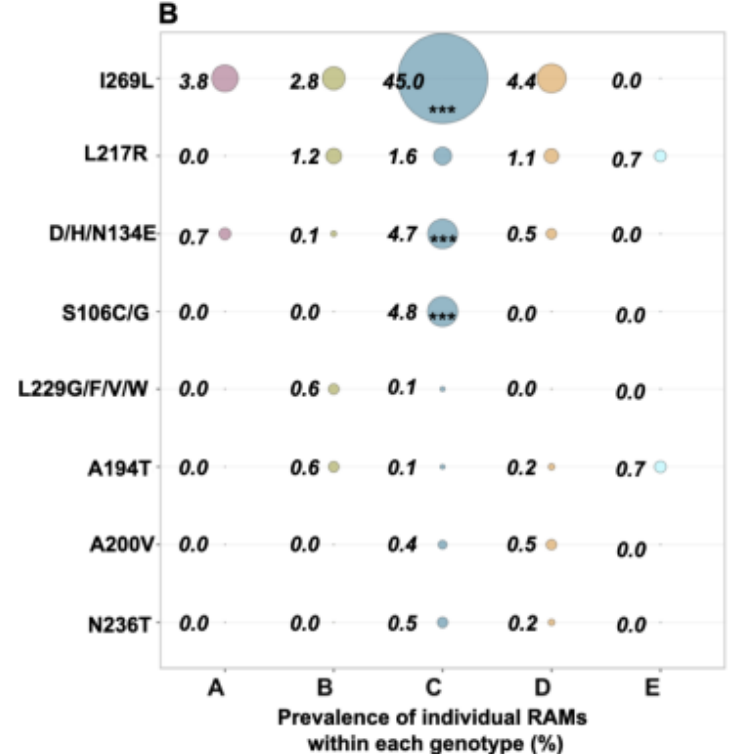

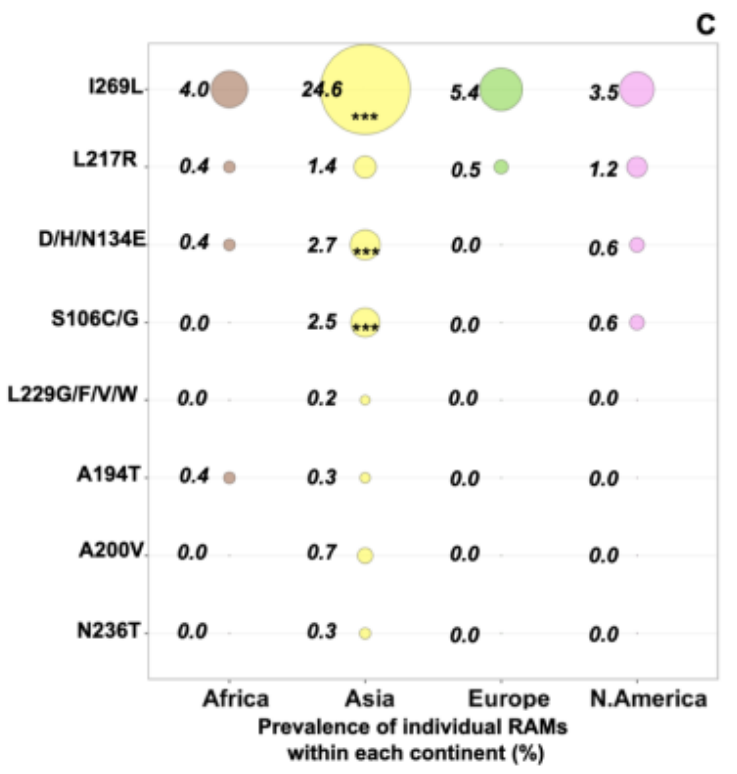

713

714
Suppl Fig 4: Global prevalence of hepatitis B virus (HBV) tenofovir (TFV) resistance associated mutations (RAMs) obtained from analysing 2838 HBV sequences with information on country of origin, downloaded from a public database (https://hbvdb.ibcp.fr/HBVdb/). A. Overall prevalence of TFV RAMs. B. A bubble plot showing the overall prevalence of TFV RAMs within each genotype (genotype A n=290; Genotype B n=730; Genotype C; $n=1102$; Genotype D n=566 and Genotype $E \mathrm{n}=150$ ). C. A bubble plot showing the overall prevalence of TFV RAMs within each continent (Africa $n=277$; Asia $n=2109$; Europe; $n=187$ and North America $n=170$ ). Numbers next to the circles are prevalence (\%) of individual RAMs in each genotype/continent. The asterisks $\left({ }^{* * * / * * / *}\right)$ within certain circles indicate RAMs that have a higher prevalence within the specified genotype/continent compared to the prevalence of that RAM in other genotypes/continents and is statistically significant. ${ }^{* *} p$ value $<0.001 ;{ }^{* *} p$ value $<0.005 ;{ }^{*} p$ value $<0.05$. Bars show $95 \%$ confidence intervals. 
A

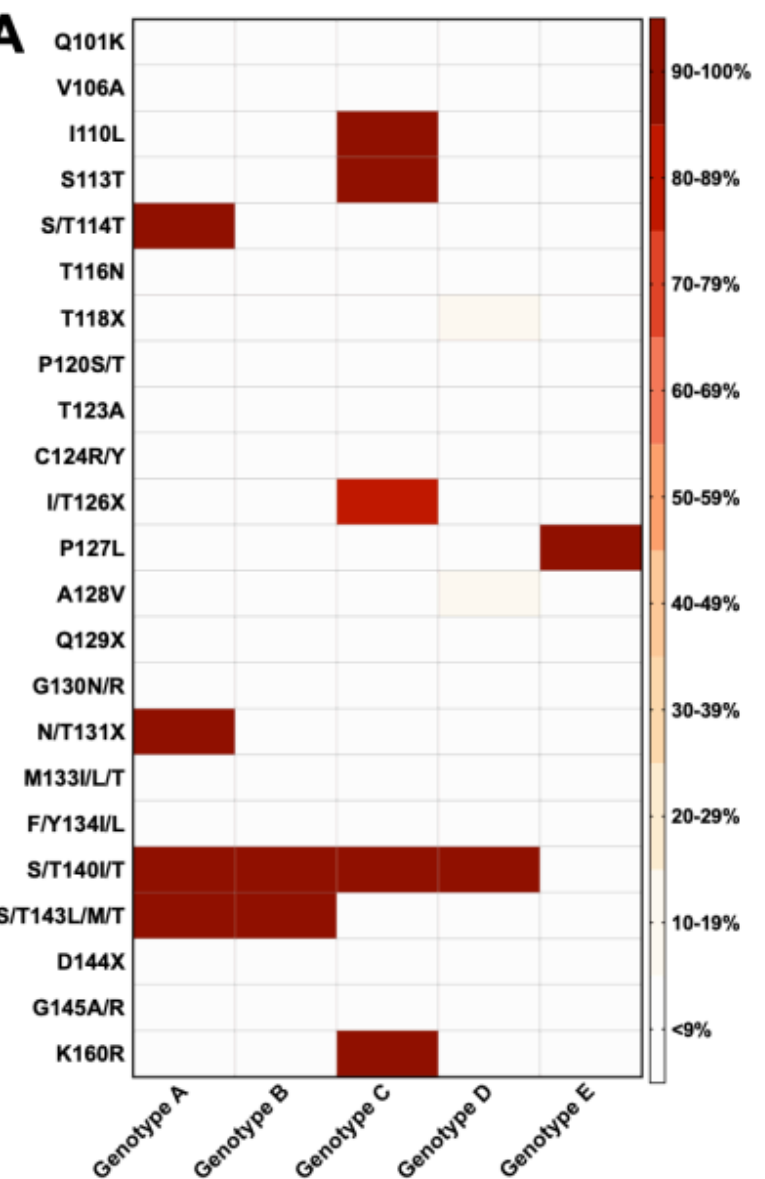

B

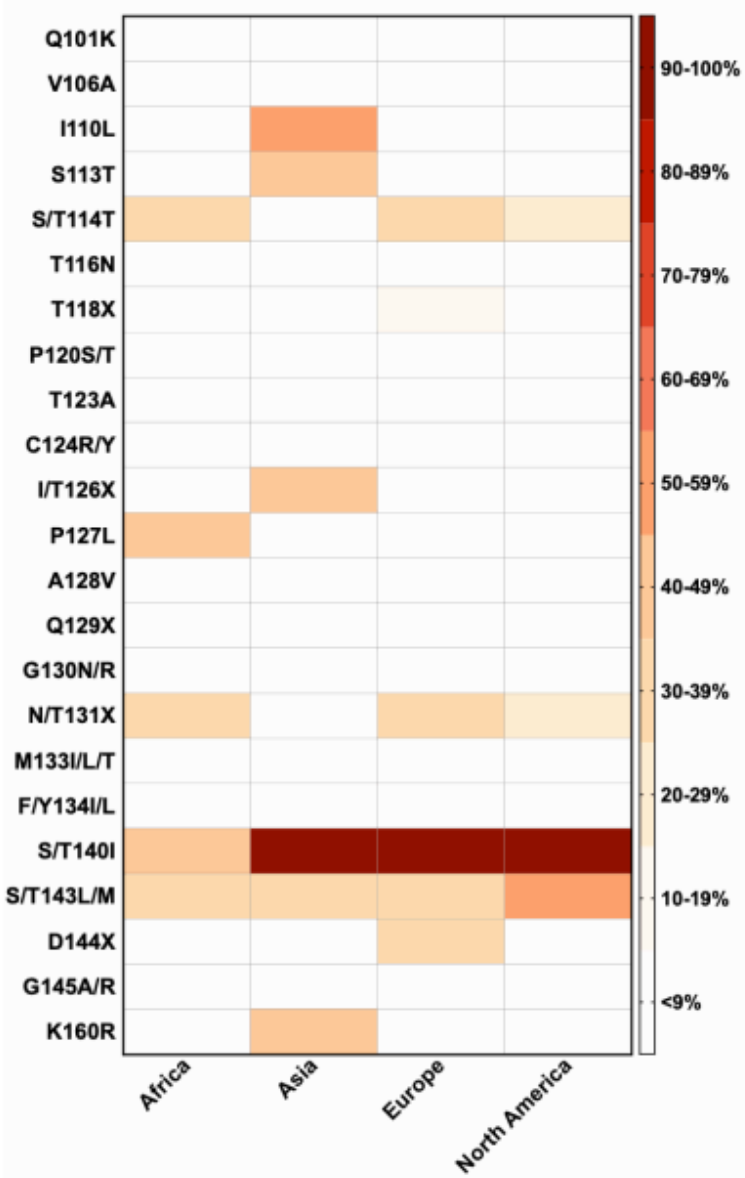

Suppl Fig 5: Global prevalence of hepatitis B virus (HBV) vaccine escape mutations (VEMs) across genotypes, obtained from analysing $2838 \mathrm{HBV}$ sequences with information on country of origin, downloaded from a public database (https://hbvdb.ibcp.fr/HBVdb/) A. Showing prevalence of polymorphisms across genotypes;

B. Showing prevalence of polymorphisms across continents. 


\section{Supplementary Tables}

733 Suppl Table 1: Hepatitis B virus drug resistance associated mutations (RAMs). Data obtained from

734 published systematic reviews $(1,2,8,9,25,31)$. Amino acid positions listed in HBV reverse transcriptase

735 protein. 3TC: Lamivudine; ETV: Entecavir; TFV: Tenofovir

\begin{tabular}{|c|c|c|c|c|c|c|c|}
\hline \multirow[b]{2}{*}{ RAMs } & \multicolumn{3}{|c|}{ 3TC } & \multirow[b]{2}{*}{ ETV } & \multicolumn{3}{|c|}{ TFV } \\
\hline & Primary & Compensatory & Putative & & $\begin{array}{l}\text { Clinical and } \\
\text { in vitro } \\
\text { evidence }\end{array}$ & $\begin{array}{l}\text { Only clinical } \\
\text { evidence }\end{array}$ & $\begin{array}{l}\text { Only in vitro } \\
\text { evidence }\end{array}$ \\
\hline $\mathrm{H} / \mathrm{Y9H}$ & & & & & & $\checkmark$ & \\
\hline V/N/S/T53N & & & $\checkmark$ & & & & \\
\hline S78T & & & & & $\sqrt{ }$ & & \\
\hline L80I/M/V & & $\checkmark$ & & $\checkmark$ & & $\checkmark$ & \\
\hline L82M & & & $\checkmark$ & & & & \\
\hline I/L91I/L & & & $\checkmark$ & & & $\checkmark$ & \\
\hline $\mathrm{S} 106 \mathrm{C} / \mathrm{G}$ & & & & & $\checkmark$ & & \\
\hline $\mathrm{T} 118 \mathrm{C} / \mathrm{G}$ & & & & & & $\checkmark$ & \\
\hline $\mathrm{I} / \mathrm{F} / \mathrm{H} / \mathrm{L} / \mathrm{N} / \mathrm{Y} 122 \mathrm{~L}$ & & & & & & $\checkmark$ & \\
\hline $\mathrm{H} / \mathrm{Y} 126 \mathrm{Y}$ & & & & & $\checkmark$ & & \\
\hline $\mathrm{T} 128 \mathrm{~A} / \mathrm{l} / \mathrm{N}$ & & & $\checkmark$ & & & & \\
\hline Q/P130S & & & & & & $\checkmark$ & \\
\hline $\mathrm{D} / \mathrm{H} / \mathrm{N} 134 \mathrm{E}$ & & & & & $\checkmark$ & & \\
\hline N/Q139D/E & & & $\checkmark$ & & & & \\
\hline $\mathrm{Q} / \mathrm{R} / \mathrm{W} 153 \mathrm{Q} / \mathrm{R} / \mathrm{W}$ & & & $\checkmark$ & & $\checkmark$ & & \\
\hline $1163 \mathrm{~V}$ & & & & $\checkmark$ & $\checkmark$ & & \\
\hline F166L & & & $\checkmark$ & & & & \\
\hline I169L/T & & $\checkmark$ & & $\checkmark$ & & & \\
\hline V173L & & $\checkmark$ & & $\checkmark$ & $\checkmark$ & & \\
\hline $\mathrm{P} 177 \mathrm{G}$ & & & & & & & $\checkmark$ \\
\hline L180M & & $\checkmark$ & & $\checkmark$ & $\checkmark$ & & \\
\hline A181T/V & $\checkmark$ & & & $\checkmark$ & $\checkmark$ & & \\
\hline $\mathrm{T} 184 \mathrm{~A} / \mathrm{C} / \mathrm{F} / \mathrm{G} / \mathrm{l} / \mathrm{L} / \mathrm{M} / \mathrm{S}$ & & $\checkmark$ & & $\checkmark$ & & $\checkmark$ & \\
\hline $\mathrm{A} 186 \mathrm{~T}$ & & & & $\checkmark$ & & & \\
\hline V191I & & & $\checkmark$ & & & $\checkmark$ & \\
\hline R192P & & & & & & $\checkmark$ & \\
\hline A194T & & & & & $\checkmark$ & & \\
\hline A200V & & & $\checkmark$ & & & $\checkmark$ & \\
\hline $\mathrm{S} 202 \mathrm{C} / \mathrm{G} / \mathrm{I}$ & & $\checkmark$ & & $\checkmark$ & & & \\
\hline $\mathrm{M} 204 \mathrm{I} / \mathrm{V} / \mathrm{S} / \mathrm{Q}$ & $\checkmark$ & & & $\checkmark$ & $\checkmark$ & & \\
\hline V/L207I/L & & & $\checkmark$ & & & $\checkmark$ & \\
\hline S213T & & & $\checkmark$ & $\checkmark$ & & & \\
\hline Q215E/H/P/S & & & $\checkmark$ & & & & \\
\hline L217R & & & & & $\checkmark$ & & \\
\hline F/Y221Y & & & & & & $\checkmark$ & \\
\hline $\mathrm{A} / \mathrm{S} 223 \mathrm{~A}$ & & & & & & $\checkmark$ & \\
\hline L229G/F/V/W & & & $\checkmark$ & & $\checkmark$ & & \\
\hline $\mathrm{N} 236 \mathrm{~T}$ & & & & & $\checkmark$ & & \\
\hline F249A & & & & & & & $\checkmark$ \\
\hline M250I/L/V & & & & $\checkmark$ & & & \\
\hline C/S256G/S & & & $\checkmark$ & $\checkmark$ & & $\checkmark$ & \\
\hline E/D263E & & & & & & $\checkmark$ & \\
\hline H/L/M/Q267L & & & & & & $\checkmark$ & \\
\hline I269L & & & & & $\checkmark$ & & \\
\hline V278I & & & & & & $\checkmark$ & \\
\hline $\mathrm{A} / \mathrm{S} 317 \mathrm{~S}$ & & & & & & $\checkmark$ & \\
\hline
\end{tabular}


bioRxiv preprint doi: $h t t p s: / / d o i . o r g / 10.1101 / 2020.10 .07 .329391$; this version posted October 8,2020 . The copyriaht holder for this preprint

(which was not certified by peer review) is the author/funder, who has granted bioRxiv a license to display the preprint in perpetuity. It is made available under aCC-BY 4.0 International license.

\begin{tabular}{|l|l|l|l|l|l|l|l|}
\hline K/Q/T333Q & & & & & & $\checkmark$ & \\
\hline N337H & & & & & & $\checkmark$ & \\
\hline
\end{tabular}

\begin{tabular}{|l|l|}
\hline RAMs common to 3TC \& ETV & I169L/T; S202C/G/I; S213T \\
\hline RAMs common to 3TC \& TFV & $\begin{array}{l}\text { I/L91I/L; Q/R/W153Q/R/W; V191I; A200V; V/L207I/L; } \\
\text { L229G/F/V/W }\end{array}$ \\
\hline RAMs common to ETV \& TFV & I163V \\
\hline RAMs common to 3TC \& ETV\&TFV & L80I/V/M; V173L; L180M; A181T/V; T184A/C/F/G/I/L/M; \\
& M204I/V/S/Q; C/S256G/S \\
\hline
\end{tabular}


737 Suppl Table 2: Hepatitis B virus vaccine escape mutations (VEMs). Data obtained from published 738 studies (1,14-16,32-39). Amino acid positions listed in HBV surface protein. VEM: Vaccine escape 739 mutation. HBsAg: Hepatitis B surface antigen.

\begin{tabular}{|c|c|c|c|}
\hline VEMs & HBIG & VEMs & Immune escape \\
\hline Q101K & & & $\checkmark$ \\
\hline V106A & & & $\checkmark$ \\
\hline I110L & & & $\sqrt{ }$ \\
\hline S113T & & & $\checkmark$ \\
\hline $\mathrm{S} / \mathrm{T} 114 \mathrm{~F} / \mathrm{R} / \mathrm{T}$ & $\checkmark$ & & $\checkmark$ \\
\hline $\mathrm{T} 116 \mathrm{~A} / \mathrm{N}$ & & $\checkmark$ & \\
\hline $\mathrm{T} 118 \mathrm{~A} / \mathrm{R} / \mathrm{V}$ & $\checkmark$ & & \\
\hline $\mathrm{P} 120 \mathrm{~A} / \mathrm{E} / \mathrm{N} / \mathrm{Q} / \mathrm{S} / \mathrm{T}$ & $\checkmark$ & $\checkmark$ & $\checkmark$ \\
\hline $\mathrm{R} / \mathrm{K} 122 \mathrm{~S}$ & & & \\
\hline $\mathrm{T} 123 \mathrm{~A} / \mathrm{N}$ & $\sqrt{ }$ & & $\checkmark$ \\
\hline $\mathrm{C} 124 \mathrm{R} / \mathrm{Y}$ & $\checkmark$ & & \\
\hline $\mathrm{I} / \mathrm{T} 126 \mathrm{~A} / \mathrm{H} / \mathrm{I} / \mathrm{N} / \mathrm{R} / \mathrm{S}$ & $\checkmark$ & $\checkmark$ & $\checkmark$ \\
\hline $\mathrm{P} / \mathrm{T} 127 \mathrm{~L} / \mathrm{P}$ & & $\checkmark$ & $\checkmark$ \\
\hline $\mathrm{A} 128 \mathrm{~V}$ & & & $\checkmark$ \\
\hline Q129H/N/R/P & $\checkmark$ & $\checkmark$ & $\checkmark$ \\
\hline G130N/R & $\checkmark$ & & $\checkmark$ \\
\hline $\mathrm{N} / \mathrm{T} 131 \mathrm{I} / \mathrm{N} / \mathrm{S}$ & $\checkmark$ & $\checkmark$ & $\checkmark$ \\
\hline $\mathrm{M} 133 \mathrm{I} / \mathrm{L} / \mathrm{T}$ & $\checkmark$ & $\checkmark$ & $\checkmark$ \\
\hline $\mathrm{F} / \mathrm{Y} 134 \mathrm{I} / \mathrm{L}$ & $\checkmark$ & $\checkmark$ & $\checkmark$ \\
\hline $\mathrm{C} 137 \mathrm{R} / \mathrm{Y}$ & $\checkmark$ & & \\
\hline $\mathrm{C} 138 \mathrm{Y}$ & & & $\checkmark$ \\
\hline C139S & $\checkmark$ & & \\
\hline $\mathrm{S} / \mathrm{T} 140 \mathrm{I}$ & $\checkmark$ & & $\checkmark$ \\
\hline K141E/I/R & $\checkmark$ & $\checkmark$ & \\
\hline P142S & $\checkmark$ & $\checkmark$ & $\checkmark$ \\
\hline $\mathrm{S} / \mathrm{T} 143 \mathrm{M} / \mathrm{L}$ & & $\checkmark$ & \\
\hline $\mathrm{D} 144 \mathrm{~A} / \mathrm{E} / \mathrm{G} / \mathrm{H} / \mathrm{N}$ & $\checkmark$ & $\checkmark$ & $\checkmark$ \\
\hline G145A/K/R & $\checkmark$ & $\checkmark$ & $\checkmark$ \\
\hline N146S & $\checkmark$ & & $\checkmark$ \\
\hline C147S & $\checkmark$ & & \\
\hline K160R & & & $\checkmark$ \\
\hline
\end{tabular}


bioRxiv preprint doi: https://doi.org/10.1101/2020.10.07.329391; this version posted October 8,2020 . The copyright holder for this preprint (which was not certified by peer review) is the author/funder, who has granted bioRxiv a license to display the preprint in perpetuity. It is made available under aCC-BY 4.0 International license.

741 Suppl Table 3: Description of sequences with individual or combination of RAMs that are highly

742 likely to cause resistance to TFV obtained from analysing 2838 HBV sequences with information

743 on country of origin, downloaded from a public database (https://hbvdb.ibcp.fr/HBVdb/). These

744 RAMs combination include $\geq 1$ RAMs from the 'short list' in combination with $\geq 3$ other RAMs from the 'long

745 list' as described (8).

746

\begin{tabular}{|c|c|c|c|c|}
\hline Sequence ID & $\begin{array}{l}\text { Individual and combination of mutations that are } \\
\text { highly likely to cause resistance to TFV }\end{array}$ & $\begin{array}{l}\text { No. of } \\
\text { sequences with } \\
\text { RAM (\%) }\end{array}$ & $\begin{array}{l}\text { Continent } \\
\text { and number } \\
\text { of sequences }\end{array}$ & $\begin{array}{l}\text { Genotype } \\
\text { and number } \\
\text { of sequences }\end{array}$ \\
\hline $\begin{array}{l}\text { GQ358144-7; } \\
\text { GQ377536; } \\
\text { KT366495; } \\
\text { GQ161771 }\end{array}$ & ${\mathrm{A} 194 \mathrm{~T}^{*}}^{*}$ & $7(0.2)$ & $\begin{array}{l}\text { Asia } n=6 \\
\text { Africa } n=1\end{array}$ & $\begin{array}{l}B, n=4 \\
C, n=1 \\
D, n=1 \\
E, n=1\end{array}$ \\
\hline FJ386681 & $\mathrm{A} 181 \mathrm{~T} / \mathrm{V}^{*}+\mathrm{N} 236 \mathrm{~T}$ & $1(0.04)$ & Asia $n=1$ & $\mathrm{~B} \mathrm{n}=1$ \\
\hline KJ803809 & $\mathrm{S}_{106 \mathrm{C}^{*}+\mathrm{D} 134 \mathrm{E}^{*}+\mathrm{Q} 267 \mathrm{~L}+\mathrm{I} 269 \mathrm{~L}^{*}+\mathrm{K} 333 \mathrm{Q}}$ & $1(0.04)$ & Asia $n=1$ & $C \mathrm{C}=1$ \\
\hline $\begin{array}{l}\text { FJ386579; } \\
\text { FJ787470; } \\
\text { FJ787471 }\end{array}$ & 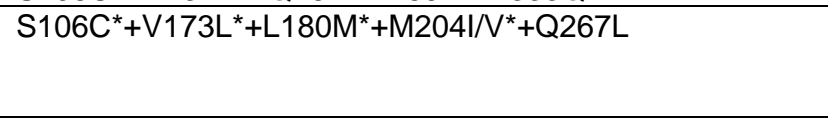 & $3(0.1)$ & Asia $n=3$ & $\mathrm{C} n=3$ \\
\hline EU939588 & 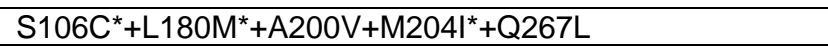 & $1(0.04)$ & Asia $n=1$ & $\mathrm{C} n=1$ \\
\hline FJ386623 & $\mathrm{S}_{106 \mathrm{C}^{*}+\mathrm{L} 180 \mathrm{M}^{*}+\mathrm{M} 204 \mathrm{I} / \mathrm{V}^{*}+\mathrm{Q} 267 \mathrm{~L}}$ & $1(0.04)$ & Asia $n=1$ & $\mathrm{C} n=1$ \\
\hline $\begin{array}{l}\text { FJ386620; } \\
\text { JX026877 }\end{array}$ & 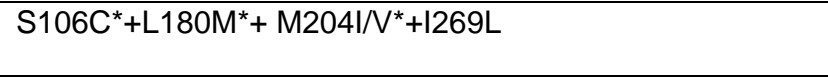 & $2(0.07)$ & Asia $n=2$ & $\mathrm{C} n=2$ \\
\hline AB182589 & 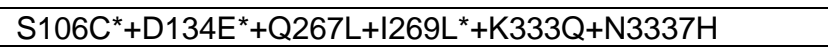 & $1(0.04)$ & Asia $n=1$ & $\mathrm{C} n=1$ \\
\hline JQ040132 & $\mathrm{D} 134 \mathrm{E}^{*}+\mathrm{L} 180 \mathrm{M}^{*}+\mathrm{M} 204 \mathrm{I}^{*}+\mathrm{l} 267 \mathrm{~L}+\mathrm{N} 337 \mathrm{H}$ & $1(0.04)$ & Asia $n=1$ & $\mathrm{C} n=1$ \\
\hline AY641561 & $\mathrm{D} 134 \mathrm{E}^{*}+\mathrm{I} 267^{\star} \mathrm{L}+\mathrm{K} 333 \mathrm{Q}+\mathrm{N} 337 \mathrm{H}$ & $1(0.04)$ & Asia $n=1$ & $\mathrm{C} n=1$ \\
\hline EU560439 & $\mathrm{D} 134 \mathrm{E}^{*}+\mathrm{Q} 267 \mathrm{~L}+\mathrm{I} 269 \mathrm{~L}^{*}+\mathrm{K} 333 \mathrm{Q}$ & $1(0.04)$ & Asia $n=1$ & $C n=1$ \\
\hline JN827423 & 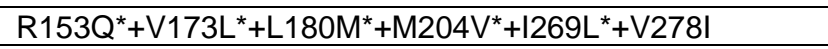 & $1(0.04)$ & Asia $n=1$ & $\mathrm{C} n=1$ \\
\hline JQ707346 & 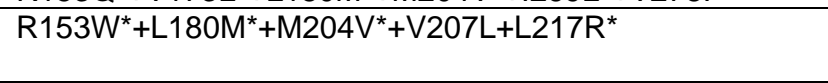 & $1(0.04)$ & $\begin{array}{l}\text { North America } \\
\mathrm{n}=1\end{array}$ & $A n=1$ \\
\hline FJ899789 & $\mathrm{R} 153 \mathrm{Q}^{*}+\mathrm{Q} 267 \mathrm{~L}+\mathrm{I} 269 \mathrm{~L}^{*}+\mathrm{V} 173 \mathrm{~L}^{*}+\mathrm{N} 337 \mathrm{H}$ & $1(0.04)$ & Asia $n=1$ & $\mathrm{C} n=1$ \\
\hline MF772345 & 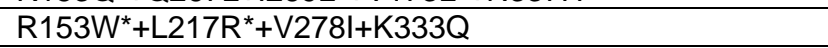 & $1(0.04)$ & Africa $n=1$ & $\mathrm{~A} n=1$ \\
\hline JN257203 & $\mathrm{R}_{153 \mathrm{Q}^{*}+\mathrm{F} 122 \mathrm{~L}+\mathrm{V} 278 \mathrm{I}+\mathrm{K} 333 \mathrm{Q}}$ & $1(0.04)$ & Africa $\mathrm{n}=1$ & $\mathrm{D} n=1$ \\
\hline KX357637 & 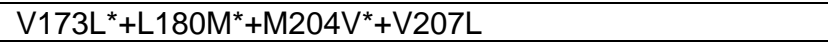 & $1(0.04)$ & Asia $n=1$ & $\mathrm{D} n=1$ \\
\hline FJ032355 & V137L+L180M+M204V+Q267L+I269L* & $1(0.04)$ & Asia $n=1$ & $\mathrm{C} n=1$ \\
\hline $\begin{array}{l}\text { JN827418; } \\
\text { JN827421; } \\
\text { MF925409 } \\
\end{array}$ & $\mathrm{V}_{137 \mathrm{~L}^{*}+\mathrm{L} 180 \mathrm{M}^{*}+\mathrm{M} 204 \mathrm{~V}^{*}+\mathrm{l} 269 \mathrm{~L}^{*}+\mathrm{V} 278 \mathrm{I}}$ & $3(0.1)$ & Asia $n=3$ & $\mathrm{C} n=3$ \\
\hline AB697490 & 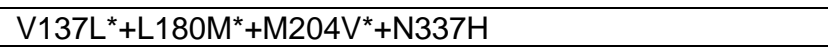 & $1(0.04)$ & Asia $n=1$ & $\mathrm{C} n=1$ \\
\hline FJ787453 & $V 137 L^{*}+M 204 V^{*}+Q 267 L+1269 L^{*}$ & $1(0.04)$ & Asia $n=1$ & $\mathrm{C} n=1$ \\
\hline FJ386604 & 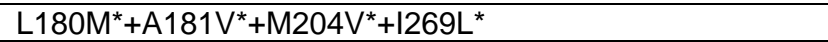 & $1(0.04)$ & Asia $n=1$ & $\mathrm{C} n=1$ \\
\hline JF828921 & 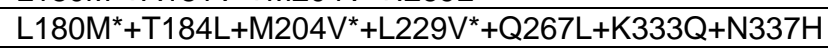 & $1(0.04)$ & Asia $n=1$ & $\mathrm{C} n=1$ \\
\hline $\begin{array}{l}\text { JF828923; } \\
\text { JF828937 }\end{array}$ & 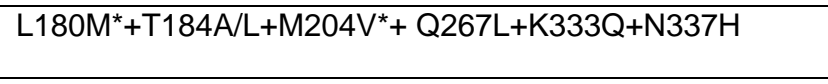 & $2(0.07)$ & Asia $n=2$ & $\mathrm{C} n=2$ \\
\hline EU939564; & 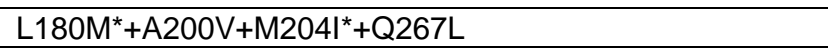 & $1(0.04)$ & Asia $n=1$ & $\mathrm{C} n=1$ \\
\hline $\begin{array}{l}\text { FJ386653; } \\
\text { FJ787455; } \\
\text { FJ787456 } \\
\end{array}$ & 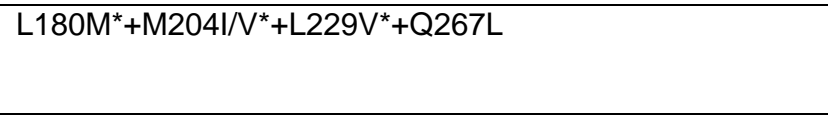 & $3(0.1)$ & Asia $n=3$ & $\mathrm{C} n=2$ \\
\hline $\begin{array}{l}\text { JN827422; } \\
\text { JN827424 }\end{array}$ & $\mathrm{L} 180 \mathrm{M}^{*}+\mathrm{M} 204 \mathrm{I} / \mathrm{V}^{*}+\mathrm{I} 269 \mathrm{~L}^{*}+\mathrm{V} 278 \mathrm{I}$ & $2(0.07)$ & Asia $n=2$ & $\mathrm{C} n=2$ \\
\hline DQ246215 & 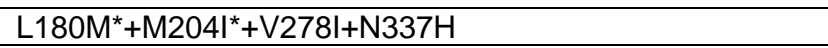 & $1(0.04)$ & Asia $n=1$ & $\mathrm{C} n=1$ \\
\hline
\end{tabular}

747 * RAMs provided in 'short list' described in (8); these RAMs are supported by the highest quality evidence

748 (i.e. isolated from treatment compliant individuals in whom viraemia was not suppressed by TFV and these

749 RAMs were also tested in in vitro assays to measure the effect of TFV on viral replication in cell lines) 
Suppl Table 4: Global prevalence of hepatitis B virus (HBV) drug resistance associated mutations (RAMs) that are wildtype amino acid. Prevalence rates were obtained from analysing 2838 HBV sequences with information on country of origin, downloaded from a public database (https://hbvdb.ibcp.fr/HBVdb/). A. Identification of RAMs as wildtype in certain genotypes using HBV reference sequences for genotypes A-J. B. Prevalence of RAMs that are wildtype amino acid across genotypes. C. Prevalence of RAMs that are wildtype amino acid across continents. HBV reference sequences were obtained from a published manuscript (68).

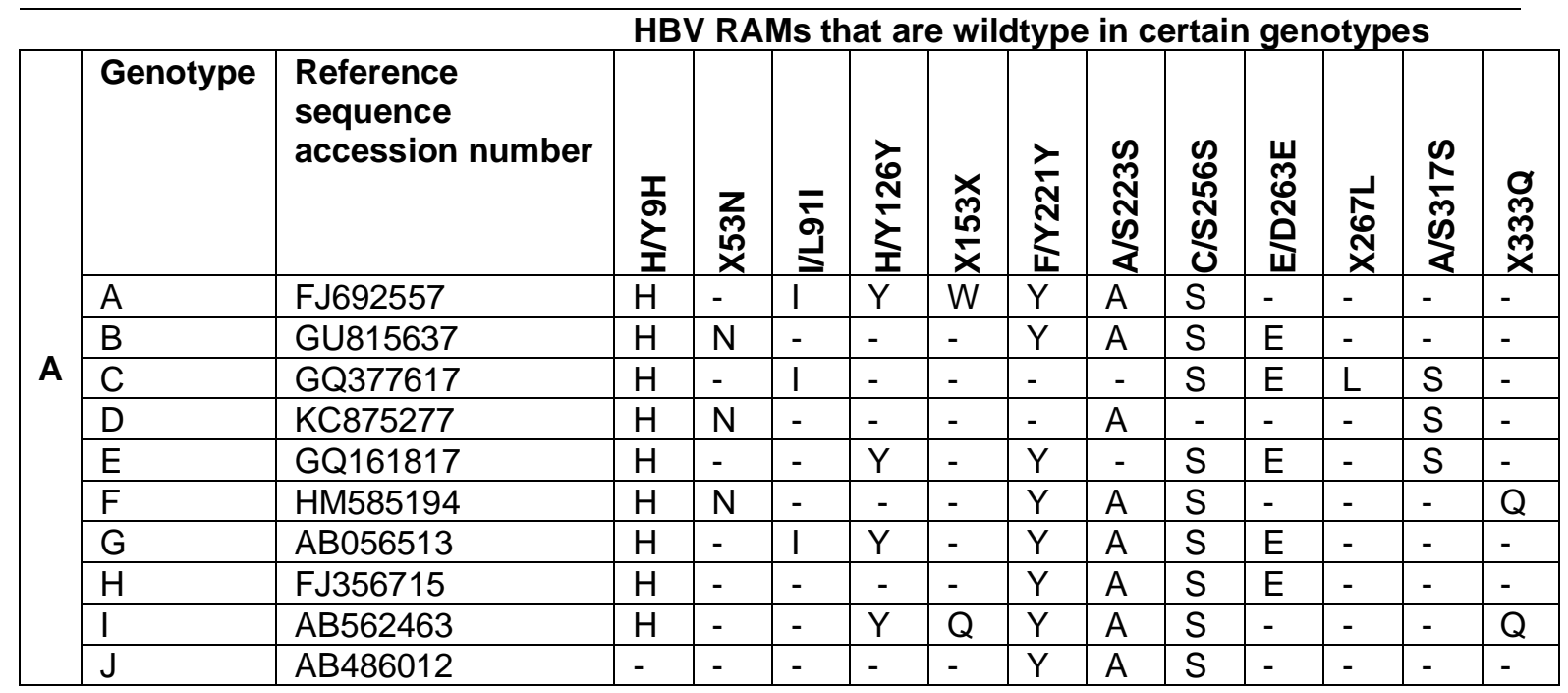

\section{Genotypes}

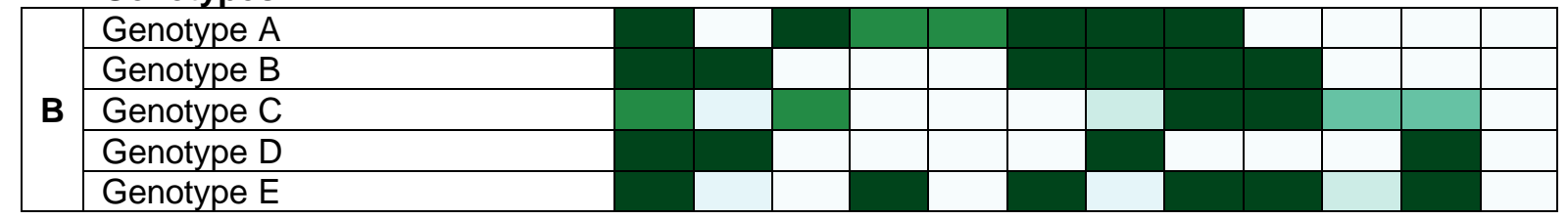

\section{Continents}

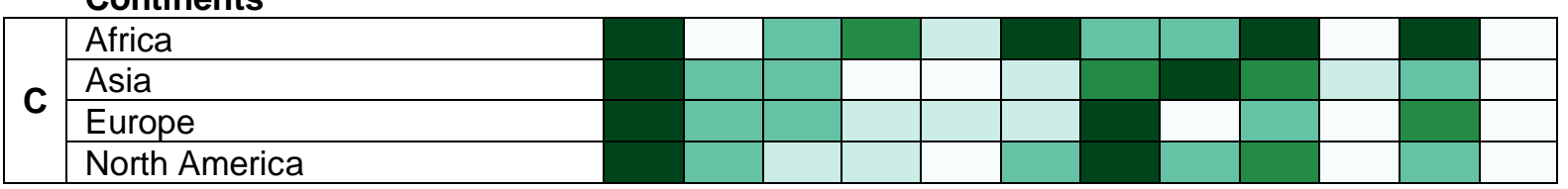

Key

\begin{tabular}{|l|l|}
\hline $81-100 \%$ \\
\hline $61-80 \%$ \\
\hline $41-60 \%$ & \\
\hline $21-40 \%$ & \\
\hline $0-20 \%$ & \\
\hline & \\
\hline
\end{tabular}



(BEAST).

We performed molecular clock phylogenetic analyses to estimate the times of emergence of mutations of interest, focussed on RAMs V173L, L180M and M204I/V as they are well known to cause (individually or synergistically) resistance to 3TC, ETV and TDF (8), and VEMs $\mathrm{G} 145 \mathrm{~A} / \mathrm{R}$ and $\mathrm{K} 141 \mathrm{E} / \mathrm{I} / \mathrm{R}$ as they have been best described to cause HBV vaccine resistance (11-13). In this analysis we included genotypes that had $>50$ sequences with associated sampling date information: genotype A ( $n=170), B(n=594), C(n=906), D(n=336)$ and $E$ $(n=88)$. We manually inspected sequences for misalignments in AliView program (43) and then excluded codon positions associated with resistance (we excluded all sites listed in Suppl Tables 1 and 2) to ensure that parallel evolution RAMs/VEMs does not affect the phylogeny (44). We first identified sequences containing these mutations on the molecular clock tree and then only focused on reporting the time to most recent common ancestor (TMRCA) of two or more sequences that clustered together having the same mutation.

782

We performed Bayesian Markov chain Monte Carlo (MCMC) analyses using BEAST v.1.10 (69). We used a GTR+G nucleotide substitution model, a coalescent Bayesian Skygrid model with 50 points (70) and the uncorrelated lognormal relaxed molecular clock model. These models were selected because they have performed best in other studies estimating HBV evolution $(46,47)$. TempEst allows quantification of temporal signal by estimating regressing the root-to-tip genetic distance of each sequence in the tree and its sampling date (48). Based on application of TempEst, we estimated the correlation between the dates of the tips of the sequences and the divergence from the root to be $7.8 \times 10^{-2}, 3.9 \mathrm{x}$ $10^{-1}, 4.3 \times 10^{-2}, 2.3 \times 10^{-2}$ and $2.1 \times 10^{-1}$ for genotypes A, B, C, D and E, respectively, and thus we elected not to estimate the molecular clock rate as there was insufficient signal in our data. We thus fixed the mean substitution rate to $5.0 \times 10^{-5}$ (SD $4.12 \times 10^{-6}$ ) and a mean standard deviation of $2.0 \times 10^{-5}$ (SD $4.96 \times 10^{-7}$ ) subs/site/year, for all genotypes in all subsequent BEAST analyses, as this rate has been estimated before and applied in phylodynamic analyses of HBV $(24,49)$.

To avoid convergence issues, we selected smaller subsamples from each of our alignments, depending on their size, to ensure that alignments used in BEAST analyses were $<200$ sequences. Thus, Genotype B (total $n=564$ ) was split into 3 subsamples, genotype $C$ (total $n=906$ ) into 6 subsamples and genotype $D$ (total $n=336$ ) into 2 subsamples. We used stratified random sampling, ensuring equal representation of 
803 sequences with mutations in each subsample. We ran one BEAST analysis for Genotypes

804 A and $E$ since their full alignments contained $<200$ sequences.

805

806 Two MCMC chains of $100 \times 10^{6}$ generations (10\% burn-in) were run with sampling every

$80710,000^{\text {th }}$ generation for genotypes $A$ and $E$, and for each subsample of genotypes $B, C$ and

808 D separately. The MCMC chains for analyses of the same genotype were combined using

809 LogCombiner v1.10.4 (69). We inspected convergence of the MCMC analyses using Tracer

810 v.1.7.1 (71) to ensure effective sample size (ESS) >200 for all model parameters. We

811 inferred maximum clade credibility trees using TreeAnnotator v.1.10.0 (69) and visualised

812 them using FigTree v.1.4.4 (69). 